\title{
LA TEORÍA DE LA JUSTICIA EN ARISTÓTELES
}

\author{
Lic. Gabriel Icochea Rodríguez \\ Profesor del Departamento de Ciencias Humanas de la \\ Universidad Nacional Agraria La Molina \\ gabrielicochea@lamolina.edu.pe
}

\begin{abstract}
Resumen
El presente trabajo es un examen de cada uno de los significados empleados por Aristóteles para definir el término justicia en el libro V de la Ética a Nicómaco. Esta taxonomía tiene implicaciones políticas.

La justicia constituye una virtud que se coloca por encima de las demás virtudes. A diferencia de las otras que tienen que ver con la vida buena y con su finalidad, la felicidad, la justicia es una virtud no vinculada a uno mismo sino a los demás. Este carácter relacional explica su condición un tanto ambigua. La ubica en un punto que es, al mismo tiempo, un intermedio entre la vida buena y el bien común, o más bien, entre la ética y la política.

Corresponde al presente texto el propósito de esclarecer los términos y las aplicaciones. Se analizan, por tanto, las diferencias entre ley (nomos) y justicia (dikaiosyne); los significados de distribución y corrección y lo relativo al intercambio y a la moneda como condiciones indispensables de la socialización.
\end{abstract}

Palabras claves: Justicia, distribución, proporción, corrección, intercambio, política.

\begin{abstract}
Abstrac
This work is a test of each one of the meanings used by Aristoteles to define the term "Justice" in the fifth book of the Ethics to Nicomaco. This taxonomy has political implications.

Justice constitutes a virtue that gains more priority than other virtues. Unlike the other virtues that have as objective the good life and with its purpose, the happiness, justice is a virtue that isn't applied to oneself but to others. This relational nature explains its conditions, which is a bit ambiguous. Its locations would be in a middle point between the good life and the common benefit, or it's most like, ethics and politics.

The purpose related to this text is one of clarify the terms and its applications. Therefore, what is analyzed are the differences between law (nomos) and justice (dikaiosyne); the meanings of distribution and correction, and which is relative to the trade and the coin as required conditions for the socialization.
\end{abstract}

Key words: Justice, distribution, proportion, correction, trade, politics. 


\section{Introducción}

El presente trabajo quiere mostrar una lectura del libro quinto de la Ética a $\mathrm{Ni}$ comaco $^{I}$ de Aristóteles. Así, pues, tiene por objeto de estudio el concepto de justicia, que en el discurso aristotélico posee el estatuto de una virtud.

Es bien sabido que Aristóteles había dividido a las virtudes en éticas y dianoéticas. Las primeras tenían su origen en el hábito; las segundas, en la enseñanza. Esta separación tiene varias implicaciones. La primera nos acerca a una teoría acerca del alma. Aristóteles había considerado en el De ánima varios tipos de alma. La primera y más precaria es aquella cuya función es puramente vegetativa; la segunda, es aquella cuya función principal es sensitiva y la tercera es intelectiva. La primera correspondería exclusivamente a las plantas; la segunda, a los animales y la tercera, al hombre 2 . Sin embargo, Aristóteles habría dado un giro al considerar el alma dividida en dos partes: una racional y la otra irracional. Dicha taxonomía tuvo validez para los tratados prácticos. Lo que se sigue de esta clasificación es la ubicación de las virtudes: las virtudes dianoéticas corresponderían a la parte racional del alma; mientras que las virtudes éticas corresponderían a la parte irracional de la misma.

Además, la diferencia implicaba, entre otras cosas, la idea bastante contemporánea de que la razón no era sólo una, sino que había distintas facultades para cada tipo de ciencia, es decir, diversas razones para objetos diferentes. Así, mientras en la doctrina esbozada en el libro VI de la Ética a Nicómaco, la facultad que nos ayuda a conocer las ciencias teóricas es el intelecto (nous); la facultad que nos acercaba a las ciencias prácticas era la prudencia (phronesis). El vínculo entre la división de las ciencias y la multiplicidad de la razón se halla fundado en una diferencia que no hace alusión tan sólo a facultades, sino a métodos distintos: mientras en las ciencias teóricas lo que se pretende es la demostración; en las ciencias prácticas se pretende la mejora de la acción.

Ahora bien, en la presente investigación pretendemos mostrar los diversos significados de la palabra justicia en el discurso del Estagirita. Si una condición problemática inaugura la lectura del libro quinto es ésta, sin duda, la equivocidad del término. Aristóteles utiliza el término justicia (dikaoisyne) de diferentes maneras. El uso del término justicia está vinculado a las diversas formas como es practicada la justicia. El realismo ético de Aristóteles acentúa la importancia, sobre todo, en las formas como la justicia es entendida en la práctica y en la vida normal de la ciudad.

Sumada a la equivocidad, tenemos el problema advertido por Oswaldo Guariglia: los capítulos habrían sido redactados en diferentes momentos ${ }^{3}$. Esta deducción proviene de un examen detallado de los diversos textos que aparecen con características desiguales: mientras los capítulos del 1 al 7 se nos presentan claros y ordenados; desde el capítulo 8 al 15, surgen redundancias insoslayables y la exposición es poseída por cierto desorden. Lo más probable es que el libro quinto, en general, haya sido recopilado por un discípulo que ubicó textos de diferentes redacciones en un libro unitario. 
Por ello, hemos destinado a la investigación tanto el primer capítulo que estudia los diversos significados que para la tradición griega anterior a Aristóteles tiene la palabra justicia, como el segundo capítulo en el que se analiza el significado de la palabra justicia para el mismo Aristóteles.

Se puede afirmar que el concepto de justicia posee implicancias políticas evidentes. Basta mirar para ello la división entre justicia distributiva y justicia correctiva. Mientras la primera se encarga de ver las relación entre el Estado y los ciudadanos (la parte y el todo); la segunda se encarga de ver las relaciones entre particulares (partes iguales) y contemplaría, por consiguiente, todo lo relativo a los contratos.

Como veremos en la investigación, la idea de la justicia distributiva cambia según el régimen político. Los criterios de distribución y, por tanto, de justicia variarían según el régimen político del que se trate. Así, en una democracia la distribución se hará para todos por igual, mientras que en una oligarquía se obrará con preferencia de aquellos que posean mayor cantidad de bienes.

En este punto, precisamente, Aristóteles introduce una noción acerca de la polis que es del todo importante resaltar. La polis es una red de intercambios que se efectúan gracias a la existencia de la moneda. Debe regir para dicho intercambio un criterio regulador que sea semejante al de la justicia distributiva. Para que haya una teoría de la polis, tiene que existir una idea sobre la moneda.
Asimismo, la justicia política señala el poder de los arcontes y la calificación de tales autoridades para administrar justicia al interior de la polis. Este punto es importante de cara a la modernidad. El Derecho moderno puede bien fundarse no sólo en el Derecho romano o en el Código napoleónico, como expresión suma de la legislación moderna, sino en las ideas esbozadas en el libro quinto de la Ética a Nicómaco. Por esto, algunos notables filósofos del Derecho como Norberto Bobbio, encuentran las primeras distinciones entre Derecho civil y Derecho penal en el discurso de Aristóteles ${ }^{4}$. En la separación entre justicia correctiva y justicia distributiva, los filósofos del derecho habrían visto la diferencia entre Derecho penal y Derecho civil.

En la realidad histórica, los significados de justicia definidos por Aristóteles habrían tenido por finalidad la justificación de una serie de mecanismos o procedimientos que ya existían en la realidad. Por esto destinaremos a ello el desarrollo del capítulo tercero. En este comenzamos con el enfoque sobre la justicia distributiva y los regímenes políticos.

Este punto nos remite a la elección del tema que está vinculada con el hecho de que la justicia constituye una virtud que se coloca por encima de las demás virtudes. A diferencia de las otras virtudes que tienen que ver con la vida buena y con su finalidad que es la felicidad, la justicia es siempre una virtud no vinculada a uno mismo sino a los demás. Este carácter relacional de la justicia permite su condición un tanto ambigua. La ubica en un punto que es, al mismo tiempo, un intermedio entre la vida buena y el bien co- 
mún, o más bien, para decirlo de forma directa, se ubica entre la ética y la política. En realidad, cada uno de los significados de la justicia es un acercamiento a esa disputa entre ética y política o entre los ideales de la vida buena y el bien común; pero en especial prestaremos importancia a los capítulos en los que abordamos la equidad (3.5) y la injusticia contra uno mismo (3.6).

¿Qué explica entonces que hayamos elegido estudiar el concepto de justicia en Aristóteles? Como hemos señalado en un trabajo anterior ${ }^{5}$, la recuperación de Aristóteles motivada por varios factores -entre los que podemos contar todos los trabajos posteriores a los descubrimientos de Werner Jaeger-, rompen con una visión sistemática y dura sobre su obra y el agotamiento o, por lo menos, la crisis del paradigma kantiano nos invitan a una nueva reflexión sobre dicho discurso. Los rescates aristotélicos han tenido en Aren$\mathrm{dt}$, en Gadamer y más recientemente en Alasdair MacIntyre intérpretes interesantes. Cada uno a su manera -y desde perspectivas distintas- recupera la obra del Estagirita. Aunque sea pertinente mencionar que todas estas recuperaciones se producen desde una tesitura crítica de la modernidad.

Es curioso que siendo la modernidad un debate contra Aristóteles, en lo tocante a su metafísica y a su lógica inherente, no muestre, sin embargo -por lo menos no en la misma intensidad-igual actitud ante la filosofía práctica. Nunca está demás repetir que discursos amplios y ricos en facetas como los de un filósofo de la estatura de Aristóteles, poseen no sólo un desarro- llo desigual, sino, además, un agotamiento desigual.

La elección del tema de la justicia también está vinculada con el hecho de que esta constituye una virtud que se coloca por encima de las demás virtudes. La condición política de la justicia nos permite acercarnos a un tópico más rico cuyas consecuencias se deben estudiar. Estar entre la ética y la política es del todo interesante más aún si notamos en el transcurso de la investigación que el libro primero de la Politica es, en realidad, una prolongación del libro quinto de la Ética.

En tercer lugar, la elección está basada en el hecho de que la justicia no es un tema que haya sido tratado por los clásicos intérpretes de Aristóteles. Apenas se le ha destinado unas páginas en las investigaciones de Guariglia o de Ghutrie. Este trabajo pretende hacerle justicia a este olvido lamentable. La indicación de la importancia de este libro es una prueba de que el tema debe ser revisado nuevamente.

Por último, debe especificarse que la oscuridad del libro amerita una investigación y un develamiento. ¿Qué otra cosa sino un develamiento de los conceptos es una misión clara de la filosofía? La presente investigación parte del hecho de que Aristóteles es un filósofo en constante evolución y, sobre todo, un partidario de la diversidad metodológica. Los libros prácticos fueron escritos para un pequeño sector de ciudadanos libres cuya actividad básica era la política y tuvieron por finalidad el mejoramiento de las acciones. ${ }^{6}$ 
Por otro lado, se tiene en cuenta la condición permanente del realismo aristotélico. Aristóteles no estaba interesado en cambiar las condiciones sociales. Su tentativa es lograr una justificación de lo que existe. Esto lo convierte de inmediato en una suerte de conservador.

El estudio ha seguido las líneas centrales impuestas por el mismo Aristóteles. Es decir, se procede a seguir cada definición y a examinarla con relación al contexto histórico. En detalle la investigación se plantea del siguiente modo:

En el capítulo primero, se verá que Aristóteles mismo es un producto de una larga tradición en la que ya se había discutido el concepto de justicia. En realidad, el Estagirita dialoga con esas tradiciones. De Homero al período clásico se discute el término "justicia". Debido a esto el presente trabajo abordará -aunque sin muchas pretensiones- el discurso sobre la justicia en algunos notables pensadores anteriores a Aristóteles. La revisión incluye no solamente filósofos, sino poetas como Homero y los trágicos. La filosofía deberá esperar la sofística para hacer suyas las preguntas relativas al hombre.

En el segundo capítulo, trataremos específicamente el discurso de Aristóteles sobre el tema. Abordaremos en, primer lugar, las cuestiones metodológicas previas que Aristóteles desarrolla generalmente en sus estudios. Luego nos ocuparemos en el segundo subcapítulo de la sinonimia que establece Aristóteles entre la justicia (dikaiosyne) y la ley (nomos). Veremos en este primer punto un vínculo que es desde luego discutible, pero que funda un primer acercamien- to político a la cuestión. La ley, es obvio, no es necesariamente la justicia. Veremos como en todo caso, cabe la posibilidad de plantear una interpretación conservadora. Es pertinente la pregunta acerca de si Aristóteles concibe leyes malas y que sea del todo justo no obedecerlas.

En el tercer subcapítulo, atenderemos a la división que establece entre justicia universal y justicia particular. En los subcapítulos cuarto y quinto abordaremos la justicia distributiva. En el subcapítulo sexto, enfocaremos la justicia correctiva. La lógica aparentemente simple de este tipo de justicia nos permitirá una comprensión fácil. En este punto seremos exclusivamente pedagógicos. Estos conceptos de justicia (distributiva y correctiva) han sido repetidamente mal comprendidos y por tanto requieren un esclarecimiento.

En el tercer capítulo, trabajaremos la relación entre la justicia y la polis. Debido a que la justicia distributiva tiene obvias consecuencias políticas trataremos de examinar en el subcapítulo primero los factores por los cuales a ciertos regímenes les corresponderá un criterio distributivo diferente.

En el subcapítulo segundo, trabajaremos una tercera forma de justicia: la reciprocidad. Vinculada a esta trataremos el tema de la moneda. Este tema resulta fundamental para la economía aristotélica la cual se hallará desarrollada tanto en este parágrafo como en el libro primero de La Política. Aquí se abordará la sociedad del intercambio, la moneda y los principios de justicia relativos al intercambio. Es justo indicar que el abordaje de este punto seńala casi 
un discurso fundador. Aquí aparecen esbozados los primeros cimientos del pensamiento económico. La economía política, que es un producto bastante posterior de la ilustración escocesa, encontraría aquí su antecesor más lejano.

En el tercer subcapítulo, trataremos la justicia política. En el cuarto subcapítulo, el vínculo controversial entre justicia natural y justicia legal. Esta división estaba conectada con el ambiente en el que Aristóteles desarrollaba su obra. Además, da origen a una tradición que tiene su mentor principal en Santo Tomás. El iusnaturalismo teológico halló en este texto su principal fundamento. En el subcapítulo quinto, abordaremos el tema de la equidad y en el subcapítulo sexto trataremos la discutible cuestión de ser injusto con uno mismo.

Poco se ha redactado sobre la justicia. La falta de interés puede tener muchas explicaciones, pero es hora de reconocer que las fuentes de las doctrinas sobre la justicia tienen su versión más organizada en el discurso aristotélico. En tiempos en los cuales los filósofos insisten en discutir el término justicia, es importante acercarse al concepto aristotélico que ya era bastante completo y que serviría para una cohabitación pacífica.

\section{La justicia en el pensamiento pre aristotélico}

\subsection{Homero y Hesíodo: la justicia como principio}

La conciencia moral es un fenómeno que se presenta de forma progresiva en el mundo griego. Por lo demás, todos los con- ceptos pasan por un trayecto de origen y consolidación. Aunque nuestra pretensión no es examinar todos los significados del concepto de justicia en la tradición helénica, abordaremos los que consideramos más importantes.

Cabe considerar el discurso aristotélico como el resultado de un largo y disputado proceso que tiene sus orígenes en la poesía épica. Esta, según una convención bastante extendida, se inicia con Homero. Son muchas las lecturas que se han hecho sobre su obra, pero es posible establecer que de sus poemas puede colegirse la idea de un orden natural. La diké es el orden natural sobre el cual reinan Zeus y los demás dioses. El ser justo implicaba llevar los asuntos según ese orden.

El orden natural y el orden social no son espacios claramente delimitados. El orden social se parece al orden natural en la medida en que se encuentra gobernado por reyes que intentan restituir, a través de sus decisiones, el orden natural gobernado por Zeus. En este sentido, el comentario de Christopher Rowe ${ }^{6}$ parece del todo pertinente: "La preocupación de Zeus muestra limitaciones semejantes: hará valer las leyes por las que se rige la humanidad, pero, por lo demás se comporta de manera semejante a la de un rey mortal y muestra el mismo interés apasionado en el mantenimiento de su honor y de su rango". En la realidad, la forma en la que Zeus administra justicia se parece mucho a la forma en que lo hace cualquier rey de aquella época.

El contexto en el que se presenta el uso del concepto de justicia tiene que ver con la toma de decisiones. Tal como sostiene 
MacIntyre: "Todos los usos de la diké en La Iliada se refieren al juicio de un juez en una disputa o a la apelación de una parte en una disputa"”.

Al concepto de diké se halla vinculado el concepto de themis como aquello que se ordena. Las órdenes deben darse conforme a una noción de justicia. La privación de lo que a una persona le corresponde o la usurpación de un derecho se considera no sólo como una infracción contra la diké, sino como una ofensa contra el honor (time). La injuria contra el honor se resuelve con la venganza. Esto explica en gran medida que los héroes homéricos estén impulsados constantemente por el afán de venganza. Un caso tomado como ejemplo es el de Aquiles contra Agamenón. En el primer canto de La Iliada, a la injuria contra Aquiles le sigue su afán de venganza. Aunque a veces no se menciona, esta forma precaria de justicia será posteriormente analizada por Aristóteles en su Etica a Nicómaco como el tipo de justicia que el filósofo denomina de "reciprocidad", es decir, la correspondencia de bien por bien (gratitud) o de mal por mal (venganza). Aunque el desarrollo de dicha forma es desechada finalmente por Aristóteles, este es el contexto en el que la reciprocidad habría sido considerada como un procedimiento correcto.

En general, MacIntyre sostiene que en la moral del periodo arcaico el cumplimiento de uno con los demás nos convierte en buenos (Aghatos) y el cumplimiento en términos de excelencia convierte nuestras acciones en areté (virtud). Sin embargo, la areté como excelencia sólo se da de forma exclusiva en el caso de los príncipes. De este modo, puede entenderse que La Ilia$d a$ sea un poema en el que los personajes centrales son príncipes.

Más cerca en el tiempo, la justicia aparece en la obra de Hesíodo como de una forma aún más importante que en Homero. En la Teogonía encontramos una representación independiente aunque esta sea puramente narrativa.

En el relato de Hesiodo acerca de la cuarta generación de los dioses se registran los distintos matrimonios de Zeus. Primero se casa con Metis (según el mito, madre de Atenea). De esta divinidad también nace Tritogenia: "Que es igual a su padre en fuerza y prudente decisión".

El segundo matrimonio de Zeus es el que llevó con Temis, "que engendró a las Horas, Eunomía, Diké y la floreciente Irene, las cuales protegen los trabajos de los hombres mortales, y a las Moiras, a las que la grandísima honra otorgó el prudente Zeus, Cloto, Láquesis y Átropon que conceden a los hombres mortales el obtener lo bueno y lo malo"s.

Según la mitografía, Diké tiene por misión central lograr el equilibrio social. Algunos comentaristas han señalado que esta representación en Hesíodo fundaría una reforma de la moralidad cuyas etapas centrales estarán marcadas por Esquilo, Eurípides y Platón.

Es menester mencionar que la conciencia moral es una proceso que tiene su esplendor en el período clásico. Antes de ello, tal como señala Mondolfo", la moral de los tiempos homéricos es una moral aristocrá- 
tica que ha enarbolado los valores propios de la guerra. Como veremos, de Homero a Hesíodo hay un tránsito de una moral aristocrática y guerrera a una moral doméstica que se extiende al hombre común y corriente. La diferencia radica en que mientras en la moral aristocrática encontramos a los actores despreocupados por la sanción; en una moral doméstica encontramos al hombre común con una preocupación enorme por la falta. No debemos olvidar que uno de los textos atribuidos a Hesíodo, Los trabajos y los días, está consagrado a Perses, su hermano, y tiene, entre otras motivaciones, la glorificación de la vida campestre.

Justamente, aquí tenemos otra mención de la justicia, pero de contenido social.

En Hesíodo hay algo más que tal vez sea excesivo calificar como utopía por su carácter exclusivamente fragmentario. Es una mezcla de mito y sociedad. Hesíodo nos brinda una semblanza de lo que implica seguir los dictados de la justicia. "Para estos que dan sentencias equitativas a indígenas y extranjeros y que no quebrantan lo justo, la ciudad es floreciente y los habitantes prosperan en ella; la paz nodriza de la juventud está sobre la tierra y jamás Zeus de amplia mirada les decreta la funesta guerra, jamás hambre ni destrucción acompañan a los hombres de equitativa justicia, sino que en las fiestas gozan de los frutos que han cultivado" 10 .

Asimismo, dice acerca de los transgresores de la justicia “(...) para estos el Crónida de amplia mirada asigna justicia. Pues muchas veces toda una ciudad participa de un hombre malo que es culpable y maquina locuras. Para estos desde el cielo el Crónida hizo descender gran sufrimiento, peste y hambre por igual y las gentes perecen; las mujeres no engendran, los hogares se aniquilan por la sagacidad de Zeus olímpico, pero otras veces el Crónida les hace perecer o bien les destruye el amplio ejército o las murallas o las naves en el Ponto" ${ }^{11}$.

Esta narrativa se resume en lo que Jaeger ha denominado "la ciudad justa y la ciudad injusta”, es decir, la comparación entre una imaginaria sociedad en la que se respeta la justicia y otra en la que se la infringe $^{12}$.

Aquí la justicia no tiene aún un contenido puramente social. La justicia será algo administrado por Zeus. La exhortación para el cumplimiento de la justicia tiene semejanzas con algunos textos propios de la literatura hebrea. Zeus en este caso se encargará de hacer justicia si los hombres no son justos de propia iniciativa. Para Jaeger, la idea del derecho defendida implícitamente por Hesíodo en este texto habría tenido su antecesor más razonable en Homero y en el Homero más próximo en el tiempo a Hesíodo que es el de La Odisea. Ya en este poeta, según Jaeger, "hallamos la creencia de que los dioses son guardianes de la justicia y de que su reinado no sería en verdad divino, si no condujera, al fin al triunfo del derecho" ${ }^{\prime 3}$.

Sin embargo, desde aquí la justicia cumple un rol de equilibrio. Desde otro punto de vista puede señalarse que empieza a funcionar la legitimación de una moral basada tanto en el castigo como en la recompensa. La justicia marca el límite entre esos dos valores. La trasgresión de la 
ley amerita castigo y la conformidad con la ley trae recompensa.

Lo cierto es que Hesíodo probablemente utilizó esta mitología para luchar contra su propio ambiente. Esto quiere decir que habría utilizado una propedéutica moral para legitimar el imperio del derecho. Más aún si se tiene en cuenta la proveniencia social un tanto adversa del poeta.

Esa lucha implica una crítica política. "Los nobles, que son los mejores (aristoi), según ellos mismos se designaban -aludiendo a sus virtudes agonales- se convierten para Hesiodo en jueces "devoradores de regalos" que sentencian torcido a favor del hermano del poeta y contra este"14. Esta explicación es coherente con otra explicación acerca del paso de una edad de bronce a una edad de hierro, en la cual se produce una desintegración de los antiguos valores. Una imagen que traduce bien esta época es la fábula del halcón y el ruiseñor: "Te tiene uno más fuerte: te despediré si quiero o bien te soltaré" 15 .

Así como a las bestias les brindó la ley de devorarse entre sí, a los hombres les dio justicia. La justicia en el contexto de Hesíodo es la defensa del débil frente al fuerte.

En Los trabajos y los días, al elogio de la justicia se une una visión positiva del trabajo, lo cual marca una diferencia con los ideales épicos de Homero.

Es importante señalar que en el Hesíodo de Los trabajos y los días se resalta también la responsabilidad de los actos humanos y en consecuencia se considera que está en manos de los hombres que sean justos o no. Es cierto que por momentos Hesiodo parece seguir en la línea de Homero, sin embargo, hay en Hesíodo un elemento mayor de libertad en las decisiones humanas. Hay un vínculo inherente entre responsabilidad y consolidación de la conciencia moral. Este punto marca también una distancia con los trágicos para los cuales el factor que decidía la naturaleza de los acontecimientos era el destino.

Un caso interesante es el de Arquíloco. Según Rodríguez Adrados, en Arquíloco aparece por vez primera la noción de ciudadano que está presente en el mismo Hesíodo aunque de forma embrionaria. En el poeta la justicia ya no aparece como una idea de eunomía o jerarquización, sino en el respeto a ciertos principios tal como se nos muestra en Hesíodo ${ }^{16}$. La firme convicción de que la ley tiene por función la protección del débil es un punto de vista que comparte con Hesíodo.

También la figura de Solón aparece entre nosotros como un factor de innovación ${ }^{17}$ Un arconte que tuvo un rol fundamental en la transformación de la aristocracia en timocracia. El exceso aparece como injusticia en Solón.

A partir de este momento se consolida el concepto de justicia en la tradición griega, la cual tendrá en el platonismo su expresión más elevada, después de la aristotélica.

\subsection{Esquilo y Herodoto}

Los temas desarrollados en las tragedias de Esquilo son el nacionalismo y la religiosi- 
dad. Sin embargo, de cara a la tradición griega, la diferencia entre Solón y Esquilo radica en que, para el primero, la justicia es algo regulado por la ley; mientras que, para el segundo, la injusticia permanece ya que comporta un aspecto de hybris (falta).

De todas formas, Rodríguez Adrados ha considerado que la concepción de Esquilo es un avance respecto de la tradición griega anterior ${ }^{18}$. Es un progreso en la medida en que se sale del contexto estrictamente político y se convierte en un tema propio de la condición humana en general.

Para algunos, la visión de Esquilo sobre la justicia es una visión relativa la impiedad. La práctica de la injusticia es una práctica de impiedad. Al decir impiedad nos estamos refiriendo a que los dioses defienden la justicia y la defienden de los mortales incluso con ira. El punto es no solamente oponerse a la voluntad de los dioses que defienden la justicia, sino en sufrir el horror que nos produce la ejecución de la misma injusticia.

Vemos en diferentes tragedias esquileas como los personajes piden a Zeus en nombre de cierta condición divina (Las suplicantes). Allí mismo se habla de la diké que asiste a las mujeres mientras que la hybris le corresponde a los transgresores de la ley que en este caso son los egipcios que pretenden casarse a la fuerza con las mujeres griegas. Como sostiene bien Rodríguez Adrados: "Aquí el término justicia no condena ya como en Solón el abuso de la adquisición de riquezas; es el derecho de la mujer al propio cuerpo lo que se defiende" ${ }^{19}$.
Hay un factor de compasión por la debilidad del hombre. Ese sería el factor que mueve a Prometeo. El ideal de justicia de Esquilo no es revolucionario, es un ideal en el que se busca un orden en el que se reconozcan los derechos, pero cuya base es religiosa como vemos.

El caso de Herodoto es diferente. Herodoto está inmerso en otra encrucijada. Este dilema es el dilema entre libertad y tiranía. Quienes imponen la dominación y por tanto incurren en injusticia son aquellos que imponen por la fuerza su poder. Los tiranos violan las leyes tradicionales y están contra la igualdad. El caso de Periandro citado por Herodoto es un ejemplo de la primera transgresión. Asimismo, en el caso de Meandrio, Herodoto dice que este critica a Polícrates por mandar a hombres que son iguales a él mismo .

También como en el caso de Esquilo, el tirano en este caso incurre en hibrys (falta). Como dice nuevamente Rodríguez Adrados: "La palabra diké tiende a exigir respeto por la igualdad humana. Meriandro por querer intentar abandonar la tiranía por las razones que citamos quiso ser el más justo de los hombres. En el discurso de Herodoto se pueden captar varios mensajes sobre la igualdad que en el discurso de Herodoto se convierte en la justicia puede ser mantener las promesas o proceder con fidelidad o tener libertad de palabra" 20 .

Sin embargo, también se conservan los antiguos usos de la diké: respeto por los dioses, la patria, los huéspedes y los heraldos. Además, se incluyen entre estas acepciones de la diké, el oponerse a la tiranía. También es notable que algunos concep- 
tos relativos a la justicia pierden su contenido religioso y se convierten en nociones puramente laicas.

El concepto de justicia que maneja Herodoto deducimos que condena implícitamente todas las formas coloniales de sometimiento como figuras propias de la injusticia. Esto se deduce de cuando nos cuenta lo que dice el rey de los etíopes: si Cambises fuera justo no desearía otra tierra que no fuese suya, ni llevaría a la esclavitud a hombres de los que no ha sufrido injusticia.

Se deduce que frente al tirano, Herodoto preconiza una triple fórmula en la que se incluya libertad, ley e igualdad. Desde el punto de vista de algunos helenistas, Herodoto al tomar distancia de una visión religiosa y al incorporar el ideal de igualdad política habría colaborado con su nueva visión de justicia a la consolidación del régimen democrático.

\subsection{Platón y el concepto de justicia}

En este punto examinaremos las diversas definiciones que Platón plantea a lo largo de su principal diálogo, La República. Las principales concepciones en torno a la justicia están planteadas en el libro primero, y en un sentido más fragmentario en el libro segundo. A partir de este hasta el libro cuarto, el objeto central de discusión gira en torno a la utopía política, es decir, a la ciudad ideal.

Algunos autores serios como Guthrie ${ }^{21}$ han considerado que el tema central tratado por Platón es el de la justicia así haya otros temas subordinados como el de la construcción de un Estado imaginario. Por lo demás, Platón insiste constantemente en recordárnoslo.

"Justicia" es la traducción tradicional de dikaiosyne, pero el término se aproxima al más amplio de los dos sentidos de la palabra definida por Aristóteles, del que dice (EN 1129b 25) que es "la virtud en su totalidad (areté) tal y como ella afecta a nuestras relaciones con los demás... (1130a9), y su contrario, la injusticia, no es parte del mal sino la totalidad...(a12). En su aspecto social es justicia, es justicia pero considerada simplemente como una característica es virtud ${ }^{22}$.

La cuestión platónica acerca de la justicia es posible plantearla porque la justicia se nos muestra como una unidad. De aquí se sigue que el hombre completamente justo sea el hombre bueno en todos los sentidos.

La idea de Christopher Rowe parece justa del todo al definir la importancia del libro primero como una pieza que nos permite introducirnos en toda la obra ${ }^{23}$. El libro primero trata exclusivamente la pregunta acerca de la justicia y una parte del libro segundo se halla consagrada al mismo tema. A pesar de la complejidad del texto y de su dificultad de reducirse a un esquema, La República puede ser dividida temáticamente de la siguiente manera: el libro I tiene por tema central la justicia; del libro II al libro IV, el objeto de investigación es la ciudad ideal; del libro V al libro VII, se trata de la educación y de la naturaleza de los gobernantes en la ciudad ideal; el libro VIII se ocupa de los regímenes políticos, de su decadencia y de las personas que los ocupan y se intenta responder a la cuestión planteada en el libro II acerca del vínculo 
entre la felicidad y la justicia, y el libro X sirve para dar añadidos y modificaciones a lo dicho. En el presente trabajo, hemos elegido los argumentos de los libros I y II por ser los que más específicamente se ocupan del problema.

El primer libro de La República empieza mostrándonos a Sócrates y a Céfalo como interlocutores. El tema de conversación es la vejez. Luego de una pregunta de Sócrates sobre las ventajas de poseer riquezas, Céfalo responde: “(...) la posesión de las riquezas contribuye en gran parte a no engañar ni mentir involuntariamente, así como no adeudar sacrificios a un dios o dinero a un hombre y por consiguiente a no marcharse con temores hacia el Hades." ${ }^{24}$ Sócrates utiliza lo mencionado por Céfalo para preguntar si él consideraría la justicia como en decir la verdad y en devolver lo que se recibe. Luego Céfalo desaparece del diálogo y su rol es retomado por su hijo Polemarco quien establece que la justicia debe ser entendida como devolver a cada uno lo que se debe ${ }^{25}$.

La dialéctica acerca del término justicia implica que se van deslizando diversos significados que se examinan detenidamente. Unos dan lugar a otros sin que se establezca de manera definitiva ningún criterio o cuando se piensa que se establece algún criterio de inmediato es sometido a una refutación.

El argumento siguiente de la discusión es una definición de la justicia, según la cual se debe devolver a cada uno lo que se debe (331e). En realidad, esto constituye una recreación de la frase de Simónides según el cual justicia es hacer bien a los amigos y mal a los enemigos. Ya veremos que esta es otra forma de plantear la reciprocidad de la que hablará posteriormente Aristóteles.

Este definición es discutida en varias ocasiones. En verdad, este es el principal argumento defendido por Polemarco. Este aserto y sus variaciones se van discutiendo en el transcurso del libro primero.

Por otro lado, uno de las ideas deslizadas en La República se halla fuertemente vinculada con el concepto de justicia particular en Aristóteles. La pregunta de Sócrates a Polemarco acerca de la función específica de la justicia es reveladora.

- “(...) ¿Respecto de qué es mejor asociarse con el justo que con el citarista?

- $\quad$ Respecto del dinero, me parece.

- Excepto tal vez, Polemarco, en cuanto se haga uso del dinero: cuando se debe comprar o vender en sociedad un caballo, es entonces más útil el entendido en caballos ¿̨no es así? (333 b,c).

Este párrafo es un punto de convergencia con la idea de justicia particular aristotélica. En verdad, la justicia puede ser vista en su totalidad como un principio que sirve para regular las transacciones económicas. La justicia en las versiones particulares de Aristóteles -como justicia correctiva y justicia distributiva- sirve, aunque no exclusivamente, para establecer un criterio de regulación de las relaciones económicas. Como veremos más adelante, tanto la distribución como la compensación se utilizan en gran medida para arbitrar los vínculos económicos. 
Pero volvamos a la idea de Polemarco: la justicia es hacer bien a los amigos y mal a los enemigos. Sócrates sostiene que la injusticia lo único que hace es reproducir la injusticia (335b-c). Si todo perjuicio lo que produce es que el perjudicado se aleje de la excelencia y la excelencia humana -entiéndase justicia- no puede crear injusticia, entonces el justo no puede perjudicar a nadie.

- En cuanto a los hombres, amigo mío, ¿no diremos, análogamente, que si los perjudicamos, se volverán peores respecto de la excelencia de los hombres?

- Ciertamente.

- ¿Y no es la justicia la excelencia humana?

- También esto es forzoso.

- Entonces también aquellos hombres que sean perjudicados se volverán necesariamente injustos.

(...)

- Y por medio de la justicia, ¿los justos pueden hacer injustos a los otros? En resumen, ¿los buenos pueden hacer malos a otros por medio de la excelencia?

- No, imposible. (335d)"

En ningún caso, el justo puede ser agente del perjuicio. Cuando Sócrates retoma el argumento anterior sostiene:

- En tal caso, si se dice que es justo dar a cada uno lo que se debe y con ello se quiere significar que el hombre justo debe perjudicar a los enemigos y beneficiar a los amigos, diremos que no es sabio hablar así, pues equivale a no decir la verdad, ya que se nos ha mostrado que en ningún caso es justo perjudicar a alguien. (335e).
Aquí parece que empieza a concluir la primera interlocución en torno a la justicia. El siguiente interlocutor es Trasímaco. Este aparece como un personaje frenético que retoma la conversación y pretende una refutación de los argumentos socráticos.

Trasímaco ha sido vinculado con Calicles el famoso interlocutor de Sócrates en el Gorgias. Como veremos, la diferencia entre los dos radica en que el primero defiende la tiranía mientras que el segundo defiende el poder al margen de la opción política que éste implique. Desde ese punto de vista, el iusnaturalismo de Calicles es lo opuesto al positivismo jurídico de Trasímaco $^{26}$. La moral natural se diferencia de el orden establecido por los hombres. La diferencia radica en una diferencia clara entre naturaleza (Physis) y convención (nomos).

Sin embargo, el personaje es interesante. Su euforia es muy notoria y es manejada por Sócrates con tranquilidad. El argumento de Trasímaco se resume en el siguiente párrafo:

Escucha pues -dijo Trasímaco-. Afirmo que lo justo no es otra cosa que lo que conviene al más fuerte. Ya ahora ¿porqué no me elogias? Pero no, no estás dispuesto a ello. (338c)

En un momento posterior, Trasímaco aclara no estarse refiriendo a ningún tipo de justicia que no sea la estrictamente política. La condición política de la justicia aborda los regímenes políticos. Hay regímenes políticos (tiranía, democracia, aristocracia) y cada uno de estos implanta 
leyes que son acordes con cada forma de gobierno.

(...) cada gobierno implanta las leyes en vista de lo que es conveniente para él: la democracia, leyes democráticas; la tiranía, leyes tiránicas y así las demás. Una vez implantadas, manifiestan que lo que conviene a los gobernantes es justo para los gobernados, y al que se aparta de esto lo castigan por infringir las leyes y obrar injustamente. Esto, mi buen amigo, es lo que quiero decir: que en todos los Estados es justo lo mismo: lo que conviene al gobierno establecido, que es sin duda el que tiene la fuerza, de modo tal que para quien razone correctamente, es justo lo mismo en todos los lados, lo que conviene al más fuerte " (339a)

Este párrafo ha sido interpretado como una primera defensa del positivismo jurídico, corriente para la cual, según las palabras de Adolf Menzel: "lo justo coincide con el derecho positivo" ${ }^{27}$. Más adelante, Trasímaco se ratifica en su defensa del positivismo jurídico cuando sostiene que los gobernantes no se equivocan.Para Sócrates las artes (techné) prevalecen sobre aquello de lo cual son artes. Digamos que en este punto se establece que el más fuerte termina equiparándose con el arte cualquiera que éste sea y el objeto del arte, con el débil. De esta forma, Sócrates sostiene que

(...) las artes gobiernan y prevalecen sobre aquellas cosas de las cuales son artes. En esto también nos pusimos de acuerdo bien que con bastante fastidio por parte de Trasímaco. Ningún conocimientoartesanal examina ni dispone lo que conviene al más fuerte sino lo que conviene al más débil, al gobernado por aquél (342c).
La analogía usada por Trasímaco en la respuesta de Sócrates es interesante: el poder es como la práctica del pastoreo. Los pastores tratan bien al ganado para su propio beneficio. En este punto, el personaje parece posesionarse de un mayor realismo político. Pero, además, en la argumentación de Trasímaco aparece un punto de flexión. Cuando compara las ventajas de la opción de la injusticia sobre la justicia, supera el espíritu del inicio que es básicamente político. El injusto deja por un momento de ser el que ejerce el poder y se convierte en un ciudadano común y corriente. Su opción le permite tener más dinero que el justo, no pagar impuestos, y cobrar más beneficios. Pero elevada a una dimensión social, la injusticia se convierte en tiranía. Bien, en este y en otros momentos se hace patente que para Platón la injusticia o la justicia no son tendencias exclusivamente políticas.

Como en el Gorgias, los interlocutores opuestos a Sócrates pasan a convertirse en apologetas de la tiranía. Lo injusto es "lo que aprovecha y conviene a sí mismo" (344 c). Esta no es sino otra definición de la tiranía. Pero Sócrates en su tentativa de refutación ha de recordar la definición de la política como búsqueda del bien de los gobernados.

(...) estoy convencido en que es forzoso estar de acuerdo en que todo gobierno, en tanto gobierno, no atiende a otra cosa que al sumo bien de aquel que es su gobernado y está a su cuidado, trátese de gobierno del estado o de ámbitos particulares (345 e).

Los hombres de bien ejercen el poder sin buscar las compensaciones del dinero, ni 
por causa de los honores. Sócrates lo dice específicamente:

(...) No quieren, en efecto, ser llamados mercenarios por exigir abiertamente un salario para gobernar, ni ser llamados ladrones (...) Y tampoco por causa de los honores, pues no aman los honores. Por eso es necesario que se les imponga compulsión y castigo para que se presten a gobernar; de allí que sea voluntario el avance voluntario hacia el gobierno, sin aguardar una compulsión. Ahora bien, el mayor de los castigos es ser gobernado por alguien peor (...) y es por temor a tal castigo que los capaces gobiernan, cuando gobiernan.

En el contrapunto entre la justicia y la injusticia vemos las deficiencias de la injusticia. Las ventajas de la justicia sobre la injusticia son que el justo no trata de aventajar a su semejante mientras que el injusto intenta aventajar tanto a su semejante como a su contrario.

Cuando Guthrie resumió los argumentos de Sócrates contra Trasímaco puso el acento en dos ideas que se siguen de los fragmentos anteriores. El primero es la consideración de Sócrates, según la cual la injusticia siempre trae discordias y odios $(350$ d). Esta condición plantea dos inconvenientes: el primero de ellos se halla vinculado con la incapacidad de obrar en conjunto y el segundo consiste en plantar una enemistad tanto consigo mismo como con otro (352 a). La imposibilidad de la injusticia se halla en que si esta se cumpliera con toda su contundencia no existiría grupo alguno ya que sus integrantes estarían enfrentados entre sí permanentemente.
El segundo punto al que Guthrie hace alusión es aquel del que habla Sócrates en 353 a. Sócrates defiende la idea de que cosa cumple su función y de este modo su excelencia. La excelencia del alma en el caso del hombre es la justicia.

- ¿Y no habíamos convenido que la justicia es excelencia y la injusticia malogro de aquella?

- En efecto.

- El alma justa, por ende, el hombre justo, vivirá bien; el injusto, en cambio, mal. (353e)

Hemos detallado los argumentos expuestos en el libro primero porque a partir de cierto momento, en el transcurso del libro segundo, la argumentación se mezcla con la construcción de la ciudad ideal.

El libro segundo es más bien un desplazamiento en la participación de los actores. Trasímaco abandona la escena y los dos hermanos de Platón, Glaucón y Adimanto, toman la posta de la discusión contra Sócrates.

Para Glaucón existen tres tipos de bienes: los que nos agradan por sí mismos como el regocijo y "los placeres inocentes"; los que nos agradan por sí mismos por lo que de ellos se genera, como la comprensión la vista y la salud; y otros bienes que son penosos, pero que deseamos poseer por los beneficios económicos o de otro tipo que nos traen, como la gimnasia o el tratamiento médico que recibe un enfermo.

La pregunta formulada por Glaucón es importante: "¿En cuál de estas tres clases de bienes colocas a la justicia?” (357d). La 
respuesta de Sócrates se inclina por la segunda opción que significa considerar a la justicia un bien que se desea tanto por sí mismo como por lo que de ellos se genera. La posición de Glaucón es la contraria: la justicia es un bien penoso que debe cultivarse con miras a obtener salarios y una buena reputación $\left(358^{a}\right)$.

Es curioso que dicha objeción ha sido ignorada por Aristóteles. El vínculo entre el placer y la justicia fue replanteado por el Marqués de Sade el siglo XVIII. No proviene de la práctica no sólo de la justicia, sino de la virtud en general, ningún placer.

El plan de trabajo esbozado por Glaucón es interesante: en primer lugar pretende responder "cómo es la justicia y de dónde se ha originado" (358 a e). En este punto -aunque no como un artificio- el argumento se aproxima mucho a la teoría del contrato. La justicia nace de la necesidad de establecer una acuerdo entre los habitantes de la sociedad para evitar padecer injusticias o como lo dice Glaucón: “(...) es el origen y la esencia de la justicia, que es algo intermedio entre lo mejor -que sería cometer injusticias impunemente- y lo peor -no poder desquitarse cuando se padece injusticia" (359a). Más aún, este acuerdo sólo puede ser llevado a cabo por los débiles que son los que pueden sufrir injusticias sin poder cometerlas.

El segundo punto defendido por el mismo personaje es que "los que cultivan la justicia no la cultivan voluntariamente sino por impotencia de cometer injusticias" (359 a b), es decir, la justicia no es un bien para aquellos que la cultivan sino tan sólo una necesidad. Ante la posibilidad de cometer injusticias y beneficiarse de ellas los hombres son iguales. Injustos y justos actúan de la misma manera. La actitud del injusto se diferencia tan sólo en la virtud para cometer injusticias. Suele el injusto ser más hábil en sus propósitos de practicar la injusticia.

En cuanto al tercer punto, se contempla que el modo de vida del injusto es mejor que la del justo. Desde el punto de vista de la habilidad que requiere toda práctica, el injusto siempre ha de ser más cauto y más diestro. Por otro lado, la práctica de la justicia tiene mucho que ver con la fama social que se adquiere cuando un hombre la practica.

En verdad, hasta aquí los argumentos son una prolongación de los que ya esbozara Trasímaco en el transcurso del libro I. Más adelante, tras la búsqueda de la justicia está la idea de entablar una noción acerca del orden político vinculado a la justicia. La justicia se ha de encontrar tanto en el individuo como en la ciudad en su conjunto. Entonces, Platón comienza la construcción de la ciudad ideal. Ya en los comienzos de la utopía vemos que Platón- al igual que Aristóteles- concibe de alguna forma una ciudad como un sistema organizado de productores que se abastecen. La ciudad surge de "necesidades puramente materiales y económicas. No hay mención alguna de la sociabilidad natural ni de la necesidad de compañía como reunidora de los hombres"28.

La existencia de una ciudad en la que se cumple la noción de justicia 
nos hace suponer que en Platón este principio es tanto más abstracto como prescriptivo.

\section{El concepto de justicia en Aris- tóteles}

\subsection{El comienzo: el método y sus im- plicaciones}

Aristóteles habría basado sus investigaciones en las opiniones del común de las personas (ese es el contenido básico de la dialéctica). En otro trabajo $^{29}$, hemos señalado la importancia que tienen para el filósofo las opiniones. Estas se sitúan casi en contraposición a la demostración, cuyo procedimiento es partir de premisas indiscutibles para llegar a conclusiones necesarias. Las opiniones, en cambio, solamente son premisas plausibles. Aristóteles habría tenido en cuenta dichas opiniones porque según se afirma no eran opuestas a los hechos. Más bien, las mismas opiniones eran la prueba de que no se oponían a la realidad ya que reflejaban el punto de vista de algunos o de muchos.

Sin embargo, debe señalarse que cuando aludimos a opiniones no hablamos únicamente de las opiniones del vulgo. Se toman en cuenta las opiniones, incluso, de los sabios. La dialéctica sería sobre todo un registro de diferencias. Las historias del pensamiento tendrían, desde este punto de vista, la imagen de una suma de disputas, de disensos dialécticos. Basta citar los libros históricos de Aristóteles -el primer libro del De anima o el libro inaugural de la Metafísica-como recuentos de controversias intelectuales.
Ahora bien, al inicio del libro quinto de la Ética a Nicómaco, el autor nos hace una advertencia:

\begin{abstract}
"Con relación a la justicia y a la injusticia, debemos considerar a qué clase de acciones se refieren, cuál es el término medio de la justicia y entre qué extremos lo justo es término medio y nuestra investigación se hará de acuerdo con el método empleado en lo que precede" (1129 a1-5).
\end{abstract}

En esta cita, Aristóteles inaugura el discurso observando dos puntos: la definición de la justicia como virtud y el método empleado. El primero consiste en considerar a la justicia como virtud, lo cual implica que siempre será un justo medio entre dos extremos. Dicha característica se halla en todas las virtudes. Todas estas son puntos medios entre excesos y defectos. Aristóteles lo ha remarcado anteriormente:
"La virtud, pues, es un hábito de la elección, que permanece en un término medio relativo a nosotros y determinada por la razón tal y como la determinaría el prudente (phrónimos)" (1106 36a 2).

Sin embargo, desde el punto de vista de Santo Tomás:

Las virtudes y los vicios ya vistos se refieren a las pasiones, pues se considera sobre todo, de qué manera el hombre es interiormente afectado por las pasiones. Ahora bien, lo que se obra exteriormente no se considera sino como una consecuencia, en cuanto las operaciones exteriores provienen de las pasiones interiores. Pero en la justicia y la injusticia se atiende sobre todo a lo que el hombre obra exteriormente. De qué manera es afectado el hombre 
interiormente no se considera, ahora, sino como una consecuencia, como alguien que es ayudado o impedido respecto de su operación ${ }^{30}$.

El comentario de Santo Tomás es interesante. Siendo un intérprete tenaz y minucioso -comentó trece obras de Aristóteles- consideraba la naturaleza de las demás virtudes - por ejemplo, la valentía- como provenientes del aspecto pasional del hombre. Es decir, su naturaleza implicaba siempre el efecto interno en el hombre.

Aunque la aparición de las humanidades es un acontecimiento decimonónico, Santo Tomás - para enfocarlo en términos contemporáneos- nos dice implícitamente que existe un giro en el que se pasa de la Psicología a la sociología de las virtudes. En verdad, decir sociología de las virtudes es advertir el carácter social de tal virtud, no asegurar que existe una explicación social de la virtud. Aunque Aristóteles crea, por otro lado, que hay condiciones - muchas de ellas sociales- que posibilitan la vida buena. Entre tales condiciones debe contarse el provenir de una buena cuna o el no ser feo ${ }^{31}$. Esto confirma únicamente el carácter aristocrático original de la ética de Aristóteles. Pero el punto es que esto advierte, básicamente, el carácter social de la justicia.

El segundo punto hace referencia al método empleado inmediatamente antes para el tratamiento de las otras virtudes. Y este consiste en una precisión de los significados. Algunos comentarios del texto dan fe de la importancia de dicha advertencia ya que la equivocidad del término "justicia”, advertida por el mismo Aristóteles, se presta a una precisión más urgente. Es necesario advertir que las discusiones sobre la justicia están vinculadas estrechamente con el contexto histórico. Por lo demás, el esclarecimiento de los significados puede ser parte de la dialéctica de las ciencias prácticas. De hecho, cada significado refleja lo que otros entienden por justicia.

Posteriormente, Aristóteles compara una noción de ciencias con una forma de ser. En esa línea, nos dice: “(...) Pues la índole de las ciencias y facultades no es la misma que la de los modos del ser: una facultad y una ciencia parecen ser las mismas para los contrarios, pero un modo de ser contrario no lo es de sus contrarios, por ejemplo de la salud solo surgen cosas saludables, pero no las contrarias, y así decimos que un hombre anda saludablemente cuando anda como lo hace el que está sano" (EN 1129a 10).

Aquí se vislumbra una diferencia entre un modo de ser y una ciencia. En esta podemos hablar de dos contrarios. Así, decimos que la filosofía se ocupa del ser y del no ser o la aritmética se ocupa de los números pares e impares. En cambio, cuando aludimos a un modo de ser sólo nos podemos referir a un modo de ser y no a su contrario. De esta manera, de lo salud solo puede provenir lo saludable o de la inteligencia solo pueden provenir cosas inteligentes.

\subsection{La injusticia como trasgresión de la ley}

Sin embargo, una primera condición empleada en el libro quinto de la Ética a $\mathrm{Ni}$ cómaco es la posibilidad de tomar en cuen- 
ta el significado de los términos por sus contrarios.

Muchas veces se conoce un modo de
ser por su contrario, pero muchas veces
también se conocen los modos de ser por
las cosas en las cuales se dan; de este modo
si la disposición buena es manifiesta, la
mala también se hace manifiesta, y la
buena disposición se conoce por las cosas
que están en buena condición y estas por
aquella (1129 a 15-20).

Este fragmento nos revela un primer punto metodológico. Es decir, a pesar de que de los modos de ser en la práctica solo se desprenden cosas parecidas a ellos, en la teoría es posible conocer los modos de ser a través de sus contrarios. Aristóteles va a ingresar al significado de los términos a través de sus significados contrarios.

Otro punto importante en la metodología aristotélica es la equivocidad del término:

(...) Ahora bien, parece que la justicia y la injusticia tienen varios significados pero por ser éstos próximos, su homonimia pasa inadvertida y no es tan clara como en los casos en los cuales el sentido está alejado... (EN 1129 a 15-20).

Esta afirmación se halla vinculada con la doctrina defendida en Los tópicos relativa a la equivocidad de los términos. Efectivamente, "llave" es un término cuya homonimia es fácilmente distinguible. Pero los diversos significados de justicia, por su parecido, resultan de difícil discernimiento.

Luego de establecer las primeras dificultades metodológicas, el autor establece las primeras distinciones:

\begin{abstract}
Vamos a considerar los diversos sentidos de la palabra "injusto". Parece que es injusto el trasgresor de la ley, pero lo es también el codicioso y el que no es equitativo; luego es evidente que el justo será el que observa la ley y también el equitativo. De ahí que lo justo sea lo legal y lo equitativo y lo injusto, lo ilegal y lo no equitativo (EN 1129 b 1-5).
\end{abstract}

En este punto, Aristóteles habla de las diversas formas en las que se manifiesta la injusticia: como codicia o como falta de equidad. Más adelante veremos que esas son las manifestaciones propias de algunas formas opuestas a ciertas definiciones de la justicia. Es decir, Aristóteles comprende, que la aplicación de la justicia requiere tanto de equidad y como de conformidad con la ley.

Sin embargo, cabe reconocer que si la práctica de la ley equivale a hacer justicia entonces es obvio que la ley contempla todas las otras formas de injusticia. Por esto dice más adelante: “(...) Pero las leyes se ocupan de todas las materias" (EN 1129 15-16). Lo cual implica que la ley sanciona todas las formas de injusticia. Ahora sabemos que el papel de reglamentación que posee la ley no abarca algunos ámbitos que son ordenados por la costumbre. Sin embargo, la visión omniabarcante de la ley en el discurso aristotélico refleja un cierto entusiasmo por las diversas legislaciones. Pero, además, es parte de una iniciativa de parte de Aristóteles por luchar contra el relativismo moral de origen sofístico ${ }^{32}$. Ya hablaremos más adelante de la deslegitimación que hace Antifon de la ley. El vínculo que Aristóteles establece entre la moral y la ley es una manera de legitimar 
la ley diciendo que ésta se halla sostenida por el principio de justicia.

Después de haber establecido que la trasgresión de la ley es injusticia, resalta el carácter político de la justicia legal.

(...) Pero las leyes se ocupan de todas las materias, apuntando al interés común de todos o de los mejores o de los que tienen autoridad o alguna otra cosa semejante; de modo que en un sentido llamamos justo a lo que produce o preserva la felicidad o sus elementos para la comunidad política (EN 1129b 15-20).

Veamos el caso de la justicia legal. Esta se encuentra vinculada a la política y a los regímenes políticos de manera inevitable. Tal como afirma Santo Tomás (...) Toda la ley se da en orden a la comunidad política. No en toda comunidad política se da lo justo en sentido absoluto, sino que en algunas se da lo justo sólo en un aspecto como muestra en la Política. En una comunidad política democrática en la cual el pueblo quiere gobernarse atiende a lo justo en un aspecto pero no a lo justo en sentido absoluto. Como todos los ciudadanos son iguales según un aspecto. Según la libertad, por eso son considerados simplemente iguales. De ahí que lo que se establece, según la ley democrática no es lo justo en sentido absoluto sino solo de alguna manera ${ }^{33}$.

Efectivamente, la cita de Aristóteles hace alusión a las leyes y de manera implícita al sistema legal que gobierna cada régimen. Al hablar de justicia legal no está refiriéndose a un objeto unívoco, sino a un conjunto de regímenes políticos cada uno poseedor de marcos legales diferentes. Ha- blar de obediencia de la ley será hablar de obediencia de leyes diferentes según cada régimen.

He aquí un punto de convergencia entre moral y política. "En el pensamiento aristotélico la obediencia a la ley es una condición sine qua non en la adquisición de la virtud de la justicia, pero siempre y cuando la prescripción legal esté a su vez contextualizada por un ideal ético" ${ }^{34}$. El ideal de la vida buena en Aristóteles sólo es posible dentro del cumplimiento de la ley. La separación entre moral y política -que desde Maquiavelo será una convención en el pensamiento moderno- tiene aquí su contraparte.

Veamos, la relación entre moral y política tiene una importancia fundamental en la tradición política de Occidente. Platón creyó que "sólo la filosofía hacía posible reconocer lo justo tanto en la vida privada como en la vida pública. No cesarán los males hasta que ocupen el poder los filósofos puros" ${ }^{15}$. Sin embargo en esa tentativa platónica de juntar moral y política acabó, según $\operatorname{Popper}^{36}$, en el pleno fracaso: nueve tiranos fueron formados en el platonismo.

En Aristóteles, hay un entusiasmo enorme por las leyes a diferencia del Platón de La República que sitúa como garantía del régimen político una casta. Aunque en el mismo Platón haya, según Dodds (Los griegos y lo irracional), una evolución en Las leyes, obra en la cual se confía fundamentalmente en la legislación.

En todo caso, la noción esbozada aquí por Aristóteles es distante del planteamiento 
de Maquiavelo para el cual la política y la moral eran dos escalas de valores distintos. Por decirlo en términos aproximados, el primero era un código ético y el segundo, un código individual.

La condición aristotélica, según Martínez Barrera, de una prescripción legal que se halle contextualizada por un ideal ético es, según vemos, muy obvia. Lo importante es establecer qué régimen es el más auspicioso de la justicia. Una respuesta posible sería inclinarse por la doctrina defendida en el libro tercero de la Política según la cual el mejor régimen es el que se denomina Politeia.

Por otro lado, es probable que Aristóteles haya considerado que la obediencia de las leyes de cualquier régimen es mejor que la desobediencia, lo cual lo sitúa en un punto semejante al de la propuesta cartesiana de una "moral provisional". Todo orden legal y el cumplimiento de dicho orden es mejor que cualquier estado fuera de la ley. De modo general, es una defensa de la comunidad política en contra del caos y también, una defensa del orden establecido. Por esto precisamente, este punto de vista suscita un profundo entusiasmo en algunos intérpretes conservadores que ven desarrollada en la perspectiva aristotélica "la función pedagógica moral de la misma ley" ${ }^{37}$.

La ley tiene en Aristóteles la posibilidad de reglamentar la vida: "La ley nos manda a vivir con todas las virtudes y abstenernos de todas las formas de maldad" (EN 1130a23-24). Así, la ley, según el mismo Aristóteles, ordena al valiente defender su posición en la batalla y no arrojar el escu- do o ser apacible y evitar las insolencias, o cometer adulterios.

Aunque ya el filósofo había mencionado las cosas consideradas malas en sí mismas en un libro anterior (EN 1107 $10-15$ ), hacia finales del libro quinto hace una diferencia entre la justicia natural y la justicia legal. La primera tendría un carácter universal mientras que la segunda sería totalmente relativa. Cabe preguntarse razonablemente si en la diversidad de legislaciones no existían algunas que no promovieran la virtud ni castigaran el vicio necesariamente.

¿Por qué Aristóteles no contempla la posibilidad de legislaciones malas? Una posible respuesta es que esté hablando únicamente de los griegos, los cuales, desde su punto de vista, habrían logrado a través de diversas legislaciones un consenso básico sobre los puntos relativos a la virtud y el vicio. Aristóteles -un profundo conocedor de las legislaciones- sabía que existían nociones básicas en las cuales todas ellas coincidían.

Otra respuesta es que Aristóteles se haya enfrentado con el relativismo de la sofística, el cual requería de una afirmación de la ley por encima de todo.

Pero una cuestión aún más inquietante es que al ser recopilador de legislaciones -las 120 legislaciones tan conocidas de las cuales sólo ha quedado la constitución de Atenas- y al considerar las disciplinas como procesos de disensos, es decir, al tener una visión histórica del pensamiento, Aristóteles no se haya percatado de la evolución de las leyes. De la legislación de 
Dracón a las legislaciones de la Ilustración hay una diferencia que implica un giro en la concepción de lo justo. Tal vez, Aristóteles no pretendía fundar un criterio histórico porque la fuerza a la que se oponía era la sofística que ya había relativizado las nociones de justicia.

\subsection{Justicia universal y Justicia particular}

Una de las distinciones más importantes es la que Aristóteles establece entre justicia universal y justicia particular. Mientras la primera tiene que ver con todo aquello que se encuentra vinculado al hombre virtuoso, la segunda es relativa al afán de lucro (EN 1130a37-38). La primera acepción es equiparable a los diversos significados que Platón le da a la justicia en el primer libro de La República.

Aquí encontramos un punto importante: ¿Por qué Aristóteles tiende a concebir que la justicia debe regular las relaciones económicas? Esta normatividad se hace necesaria ya que Aristóteles posee la convicción de que la sociedad es un sistema de intercambio tal como veremos más adelante. Así como se hizo notorio en la parte dedicada a Platón que el principio de justicia servía para regular los intercambios económicos; del mismo modo aquí en Aristóteles la justicia particular pretende fundar un criterio a partir del cual podamos regular dichos intercambios. Aunque, tal como ha señalado el mismo Aristóteles en líneas anteriores, no sólo es arbitrado el tema económico sino las actividades que tienen por finalidad, el honor o la seguridad. Estas instancias, sin embargo, dependerán inexorablemente de un sustrato económico.
La justicia particular está dividida en justicia correctiva y en justicia distributiva. La primera pretende establecer una compensación que iguale al daño cometido entre dos partes equivalentes, mientras que la segunda establece un criterio de distribución social. Este por lo general implica a la entidad estatal. El Estado tiene la facultad de distribuir bienes entre los ciudadanos (honores, dinero, etc).

La relación entre individuos iguales se divide al mismo tiempo en tratos voluntarios e involuntarios: "Los voluntarios son tratos tales como el de compra, venta, préstamo de dinero, fianza, usufructo, depósito, alquiler (y se llaman voluntarios por que son iniciados voluntariamente); de los involuntarios unos son llamados clandestinos como el hurto, adulterio, envenenamiento, prostitución, sedición de esclavos, falso testimonio y otros son violentos, como el ultraje, el encarcelamiento, el homicidio, el robo, la mutilación, la difamación y el insulto" (EN 1131 a 4-11).

El esquema que suele representar bien esta división es el que varios especialistas como Guthrie o Guariglia han empleado:

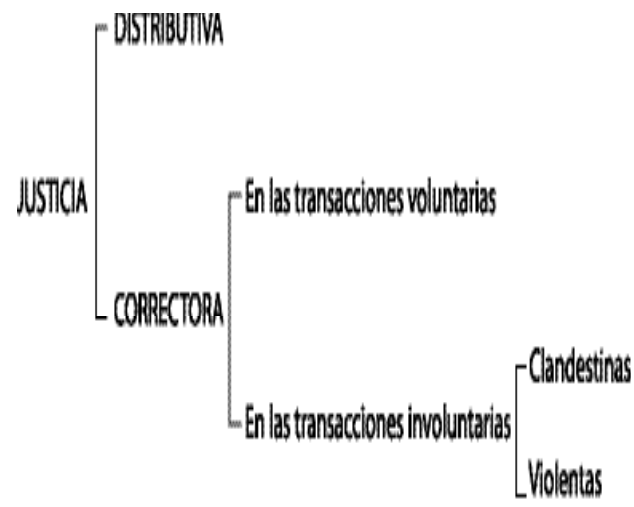




\subsection{La justicia distributiva}

El propósito de Aristóteles en este punto es establecer un esquema, es decir, un criterio formal a partir del cual pueda enfocar los diversos casos de justicia. Aquí un primer problema lo constituye el abandono del criterio seguido por Aristóteles para las otras virtudes. Es decir, el término medio resulta insuficiente. Sin embargo, tal como comenta Guthrie, el justo medio en el caso de la justicia se relativiza excesivamente ${ }^{38}$. No existe ninguna adaptación entre el término medio como virtud y la justicia. Otros intérpretes como Newman consideran que "el propósito fundamental del libro quinto es probablemente mostrar que la justicia como todas las demás virtudes morales tienen que ver con el término medio, que ella es analogón y os logós (ya que en griego la palabra que se usa para razón y proporción es la misma) y que tiene más de una clase"39.

Ahora bien, se ha señalado el principio de justicia como un justo medio. El término medio, en este caso será, proporcional a la persona y al bien del que se trate. El término medio funciona en la justicia distributiva como proporción.

(...) De acuerdo con ello, necesariamente, lo justo será un término medio e igual en relación con algo y con algunos. Como término medio lo será de unos extremos (es decir, de lo más y lo menos); como igual, respecto de los términos y como justo, en relación con ciertas personas. Por tanto, lo justo deberá requerir, por lo menos, cuatro términos: pues aquellos para quienes es justo es dos y las cosas en las que reside también son dos (EN $1131^{\text {a } 15-20) . ~}$
Es decir, tenemos un par de individuos ( $\mathrm{X}$ e Y), a los cuales les son proporcionales dos cantidades de bienes. Según sea cada individuo y según sea el criterio de repartición, a un individuo $\mathrm{X}$ le tocará un conjunto de bienes y a un individuo $\mathrm{Y}$ le tocará un conjunto de bienes diferente. Sean $\mathrm{X}$ e $\mathrm{Y}$ los individuos y $\mathrm{Z}$ y W los bienes. Deberíamos decir en términos formales lo siguiente: $X: Z=Y$ :W. Lo cual puede ser leído como: a $X$ le corresponde la cantidad de bienes $\mathrm{Z}$ así como a $\mathrm{Y}$ le corresponde la cantidad de bienes $\mathrm{Y}$.

Los términos de la proporción serán siempre cuatro. De esta manera, podemos decir que la cantidad de bienes que le corresponde a un individuo es proporcional a la cantidad de bienes que le corresponde a otro:

término medio y lo justo es proporcional. Los matemáticos llaman a tal proporción geométrica, en efecto en la proporción geométrica, el todo está con respecto al todo, en "(...) y esta justicia es un término medio en la proporción , porque lo proporcional es un la misma relación en que cada parte con respecto a cada parte" (EN 1131 n. 8-13).

En la justicia distributiva lo que rige es una relación geométrica entre los individuos y los bienes. En realidad, este esquema sirve para fundamentar el vínculo entre los individuos y el Estado. En la repartición de bienes, digamos, de bienes como el trigo ¿Qué tipo de reparto correspondería? La relación ya no es entre iguales, sino entre el Estado y los individuos ¿Qué tipo de distribución deben hacer los Estados de los bienes entre sus ciudadanos? 
Hemos mencionado bienes materiales, pero en verdad no sólo son bienes de este tipo los que se repartían en la sociedad antigua. Deben añadirse a estos, los cargos públicos, los honores y el mérito. De todo lo mencionado, no cabe duda de que lo menos relativo y lo más actual es la incompatibilidad entre el mérito y la igualdad. El mérito es un tipo de justicia que toma distancia de la visión corriente acerca de la igualdad. La cantidad de bienes -sean estos materiales o simbólicos- deben ser proporcionales al mérito y esta condición crea inmediatas desigualdades, que pueden ser, desde un punto de vista aristotélico, desiguales pero justas. Para denominarlas existen los términos de "igualdad proporcional" utilizada por Guariglia que alude en verdad a una igualdad diferente de la convencional. Sin embargo, tal como el mismo Aristóteles apunta, el concepto de mérito se encuentra vinculado con los regímenes políticos.

En términos generales, la distribución perdura como un punto de controversias. En la sociedad actual, la discusión en torno a la distribución toca dos puntos de discusión. El primero es el que conoció el mismo Aristóteles ¿Cómo repartimos los bienes de la forma más legítima? Al formular la pregunta es deducible por el tenor del discurso del mismo Aristóteles la falta de consenso en su tiempo en torno al punto (en la época de Aristóteles estos bienes provenían por lo general de las conquistas de la ciudad o de los donativos hechos a la misma). La respuesta, como veremos adelante, toca el punto relativo a los regímenes políticos.
Pero el segundo punto de controversia relativo a la distribución es el que señala al órgano distribuidor que desde los tiempos de Aristóteles hasta la actualidad ha sido el Estado. Sin embargo, posturas como las de la escuela austriaca o la escuela de Chicago señalan ya no al Estado, sino al mercado no solo como el asignador principal de recursos, sino como el exclusivo distribuidor de recursos. Por supuesto que esto se da en los marcos de una utopía política.

\subsection{La justicia correctiva}

La justicia correctiva (To diorthotikón) es el fundamento a partir del cual examinamos los vínculos entre las personas. Aristóteles la diseñó originalmente para las relaciones tanto voluntarias como involuntarias. Es decir, toda relación -consentida o no- entre particulares o entre iguales es ubicada conceptualmente al interior de este tipo de justicia. Aunque el filósofo considera que existe una diferencia entre los intercambios voluntarios y los involuntarios hay un término común que abarca a estos dos tipos de actos. Esto le hace a Guariglia decir que el término griego para estas relaciones es sumamente amplio (synallagma).

También en la justicia correctiva existe el propósito de establecer un criterio formal desde el cual podamos efectuar un juicio para cualquier caso particular. Hemos visto más arriba que la justicia distributiva está basada en la proporción geométrica. Por el contrario, el tipo de igualdad que en este punto defiende Aristóteles es una igualdad que está basada en la proporción aritmética. La diferencia obvia es que mientras la justicia proporcional es 
un tipo de justicia que contempla en la realidad las relaciones entre el Estado y los individuos; la justicia correctiva contemplará solamente la relación entre dos individuos iguales.

Por otro lado, se toma en cuenta que el sujeto permanente que decide el principio de justicia es un juez. En torno al punto, uno de los aspectos que resultan controversiales es la confianza que Aristóteles ha puesto en los jueces. El juez debe haberse convertido para esto en un perfecto phronimós.

Debido a que la relación es entre iguales se considera que lo que debe definirla es una política de compensación. La compensación debe ser equivalente con el perjuicio.

De suerte que lo igual es un término medio entre lo más y lo menos y la ganancia y la pérdida son más y menos en sentido contrario, porque la ganancia es el bien mayor o el mal menor, y la pérdida lo contrario. El término medio de estos era lo igual, lo cual decimos que es lo justo, de modo que la justicia correctiva será el término medio entre la pérdida y ganancia (EN 1132a 15-20).

Aristóteles ha graficado este tipo de justicia con el uso de la línea. Es importante reproducir el gráfico utilizado en su exposición :

E

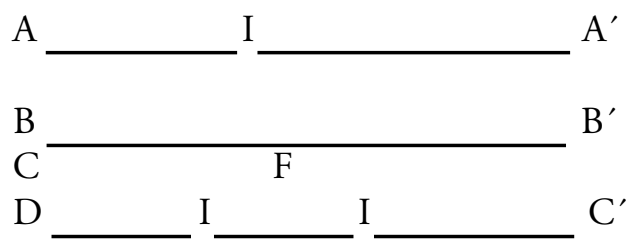

"Sean las líneas $\mathrm{AA}^{\prime}, \mathrm{BB}^{\prime}, \mathrm{CC}^{\prime}$, iguales entre sí ; quítese de la línea $\mathrm{AA}^{\prime}$ el segmento $\mathrm{AE}$ y añádase a la línea $\mathrm{CC}^{\prime}$ el segmento $C D$, de modo que la línea entera $\mathrm{DCC}^{\prime}$ exceda a la línea $\mathrm{EA}^{\prime}$ en los segmentos $\mathrm{CD}$ y $\mathrm{CF}$; excederá entonces, a la línea $B B^{*}$ en el segmento CD.” (EN $1132^{\mathrm{b}}$ 5-10).

Lo que se entiende es que se produce en este gráfico una operación de compensación.

Las palabras "ganancia "y "pérdida" proceden de los cambios voluntarios pues a tener más de lo que uno poseía se le llama ganar y a tener menos de lo que tenía al principio, perder, y lo mismo en el comprar, en el vender y en todos los otros cambios que la ley permite, en el vender y en todos los otros cambios que la ley permite; y cuando dos partes no tienen ni más ni menos sino lo mismo que tenían, se dice entonces, que tienen lo que pertenece a cada uno y que no pierden ni ganan. (EN 1132b 10-15).

Este es el tipo de justicia que posee mayores posibilidades de ser comprendida. Sin embargo, hay un debate entre los intérpretes cuando consideran que Aristóteles pudo estar siguiendo únicamente lo que era el procedimiento normal en los juzgados griegos, mientras otros sostienen que dicho procedimiento no era en absoluto una práctica común forense entre los griegos. Entre los primeros se inscriben Hamburger y Joachim; en las segundas posiciones, Gernet y Harrison. Guariglia ${ }^{40}$ se inclinan a pensar que las ideas de Aristóteles deslizadas en su tratado no tenían un correlato práctico, no tenían nada que ver con la práctica del derecho en Atenas. No obstante, es fácil hallar dichos procedi- 
mientos al interior del derecho romano en la distinción establecida entre obligaciones ex contrata y obligaciones ex delicto. Si fuese verdad que Aristóteles nunca copió el modelo griego tendría por eso mismo más mérito ya que su carácter fundacional sería más evidente.

\section{La justicia y la polis en Aristóte- les}

\subsection{La justicia distributiva y los regí- menes políticos}

Se ha de ver como una de las implicaciones más importantes de la justicia distributiva es aquella que la vincula a los regímenes políticos. Los criterios de distribución están dados por el tipo de régimen. Esta condición relativa al mérito es muy explícita en el mismo Aristóteles:

(...) pero no todos coinciden en cuanto al mérito mismo, sino que los demócratas lo ponen en la libertad, los oligárquicos en la riqueza y en la nobleza y los aristócratas en la virtud (EN 1131a 27-30).

En el libro octavo de La República, Platón divide los regímenes políticos en Oligarquía, Timocracia, Democracia y Tiranía. La visión de los regímenes es cíclica. La decadencia de unos, conduce a otros. Así, el colapso del régimen democrático daría origen a la tiranía. Aunque no lo propone de forma explícita, es probable que Platón haya considerado, que la sucesión de regímenes era un círculo vicioso del que sólo podía salirse a través de la instauración del tipo de aristocracia que él proponía. Sin embargo, en su condición de utopía, esta se hallaba fuera del tiempo, a pesar de sus tentativas reales por llevarlas a la práctica, según leemos en la Carta Séptima. Es obvio que la consecución de un régimen dirigido por una casta de guardianes entrenados en filosofía daba fin a la circularidad de los regímenes por su carácter de perfección. Lo perfecto no cambia, es inmutable. En esta característica se encuentra, además, su naturaleza utópica.

Por otro lado, es digno de resaltar que ya en el discurso platónico cada régimen se halla fundado en ciertos valores. De esta manera, en la oligarquía lo que seńala el poder es la posesión de bienes. Del mismo modo, en la democracia los valores de la igualdad y la libertad dan la pauta del vínculo con el poder. Es decir, en una democracia todos son libres e iguales; todos pueden ejercer el poder indistintamente y ser, al mismo tiempo, gobernantes y gobernados. La desconfianza platónica, hacia estos valores, se manifiesta en su argumento de que la igualdad disuelve el principio de autoridad. Si todos son iguales no podrán mandar unos sobre otros. Los hijos no podrán obedecer a los padres ${ }^{41}$, ya que siendo iguales no tendrían porqué unos obedecer a otros.

Es conocido que Aristóteles considera en La Politica ${ }^{42}$ seis regímenes separados, que en verdad son tres parejas de modelos. Uno constituye una versión buena y el otro, una versión mala de cada uno. El principio de distinción es de número ${ }^{43}$ : el gobierno de uno positivo es la monarquía mientras que su expresión degenerada es la tiranía; la versión positiva del gobierno de algunos es la aristocracia mientras que 
su versión deteriorada es la oligarquía y la versión positiva del gobierno de todos es la politeia mientras que su versión deteriorada es la democracia.

Ahora bien, cada régimen importa nociones diferentes relativas a la distribución. La distribución del poder, para no hablar de la distribución de los bienes, encuentra aquí una diferencia muy evidente. Mientras en una oligarquía los valores de la distribución favorecen a todos aquellos que son poseedores de muchos bienes; en una democracia la distribución beneficia a todos.

Todo el mundo está de acuerdo -dice Aristóteles- que la justicia en la distribución ha de estar conforme con el merecimiento de algún tipo, dónde no están de acuerdo es en el tipo de merecimiento que tiene que $\operatorname{ser}^{44}$.

Sobre el punto, MacIntyre acierta al sostener que no se puede entender la teoría de la justicia de Aristóteles, sin antes comprender su teoría de la acción práctica. Las exposiciones sobre la justicia en Aristóteles apenas hacen referencia alguna a su versión del razonamiento práctico.

(...) Mi tesis central es que el pensamiento de Aristóteles acerca de cada uno de estos temas es inteligible sólo a la luz de lo que dice acerca del otro (refiriéndose a la teoría de la acción y a la teoría de la justicia) ${ }^{45}$.

El ejercicio de los cargos, es decir, del poder estará acorde con la excelencia, es decir, con la virtud. Como ya vimos en La Política (Libro I), Aristóteles rechaza de plano que puedan ser las mujeres, los siervos o los hombres jóvenes quienes ejerzan el poder. El logro de la excelencia está limitado para todos los mencionados. En algunos casos, el impedimento se explica por la falta de experiencia como en los jóvenes; en otros casos, por un impedimento natural, como en los esclavos.

Ahora bien, hemos de recordar que de las dos formas de justicia expuestas, la justicia distributiva es la que se encuentra vinculada con la distribución del poder. Según MacIntyre: "La justicia distributiva, entonces, consiste en la aplicación de un principio de merecimiento a una variedad de tipos de situaciones. Pero los conceptos de merecimiento tienen aplicación sólo en los contextos en los que se satisfacen dos condiciones. Debe haber alguna empresa común en el logro de cuyas metas los que se consideran más merecedores han contribuido más que los que se consideran menos merecedores; y debe haber una opinión compartida tanto de cómo tales contribuciones han de medirse como de la manera en que las recompensas han de asignarse" ${ }^{46}$. Y no sólo deben medirse según las personas los merecimientos positivos, sino también los castigos.

\subsection{Una tercera forma de justicia: la re- ciprocidad}

Aparte de las formas conmutativa y distributiva, existe la forma de justicia que se denomina de "reciprocidad" (to antipevonthos). Esta corresponde con una noción pitagórica según la cual la justicia es reciprocidad. 
Pero la reciprocidad no se compagina ni con la justicia correctiva ni con la distributiva, aunque se quiere interpretar a favor de esta identificación la justicia de Radamantis: si el hombre sufriera lo que hizo habria recta justicia (EN $1132^{\mathrm{b}} 20$ ).

Algunos intérpretes se esmeran en afirmar la oscuridad de dicho texto. Pero tal como explica Carnes Lord: "en este sentido la justicia parece abarcar a la vez la simple venganza por dańos recibidos y el intercambio de bienes" ${ }^{\prime 4}$. Dicho punto de vista parece sostenerse. Las dos partes a las cuales alude el texto tienen que ver con dos posibles formas de reciprocidad. Una de ellas es la venganza; la otra, la gratitud. La sugestiva idea - por lo demás bastante vinculada a la sofística y al pensamiento que relativizaba la moral-, según la cual la ley es sólo una forma de venganza, encuentra aquí una problematización adecuada. La mención a los pitagóricos anota una primera forma de reciprocidad, el autor nunca señala cuál es la fuente consultada para su referencia. En un segundo nivel, sin embargo, la venganza juega un papel fundamental en la moral del período arcaico. Los héroes homéricos movilizados dentro de un contexto de guerra consideran que la forma a través de la cual se restituye la justicia es a través de la ejecución de un daño que suplante el daño recibido. La lógica de la misma guerra es la de restitución del daño.

Como bien señala Mondolfo: "La justicia de los tiempos homéricos (como lo han observado Hirzel y Max Wunt y para nombrar otros, Bill y Jaeger) es virtud aristocrática que concierne en sus relaciones con el débil. Virtud de los héroes, para quienes como dice Ulises en la Odisea (IV, 214 y ss.) son nobles los actos de guerra, no el trabajo ... no la actividad doméstica, la cual cría aseados a los niños" ${ }^{48}$. La lógica de la guerra es la lógica de la restitución de los daños por otros daños semejantes. Así tales daños sean agravios o faltas al honor. Basta citar la venganza fallida de Áyax o el filicidio de Medea como buenos ejemplos de restitución.

Por lo demás, ya en la mentalidad antigua se percibirá un giro de Homero a Hesíodo que retorna a los valores simples de la vida campesina. En dicho cambio, se reflejan algunos principios importantes. Los héroes homéricos no se hallan preocupados por la consecuencia de sus actos; mientras que el campesino sencillo reconstruido por Hesíodo en Los trabajos y los días está preocupado por las consecuencias de sus acciones ${ }^{49}$. Esta diferencia radica en una lógica de la venganza que da paso a la instauración de la ley. Mientras el héroe homérico se moviliza a través del patrón de la costumbre, el campesino se mueve dentro de cierto precario marco legal.

Aristóteles es consciente del origen antiguo de esta forma de justicia. La falta de algunas consideraciones de esta forma de justicia revelaría su origen elemental.

Por ejemplo, si un magistrado golpea a uno, no debe a su vez ser golpeado por éste, pero si alguien golpea a un magistrado no sólo debe ser golpeado, sino también castigado (EN 1132 $\left.{ }^{\mathrm{b}} 25\right)$.

Este primer ejemplo expresa la validez de la justicia distributiva que considera un trato diferente para una autoridad. Eso 
explica la diferencia en el trato porque mientras una persona común y corriente puede ser tratada de cierta forma, en una autoridad se castiga además la actitud contra su investidura. El rechazo al principio de la justicia como reciprocidad halla una incompatibilidad con la justicia distributiva. Como afirma Santo Tomás en uno de sus comentarios: "Lo justo distributivo no se alcanza según que uno de los dos, que deben ser igualados por la justicia actúe por otro o padezca por otro, lo cual es requerido por la noción de reciprocidad, sino según que algo de los bienes comunes sea distribuido a ambos según una igualdad proporcional ${ }^{50}$.

Una segunda observación de Aristóteles nos dice: "Hay además aquí una diferencia entre lo voluntario y lo involuntario". Aquí se pasa a la lógica del intercambio y esto a la lógica en general de la moneda. Si la sociedad es una sociedad de intercambios, este intercambio se encuentra fundado en la moneda.

\subsection{La reciprocidad y la moneda}

El caso de la moneda es un punto que marca una diferencia fundamental entre Platón y Aristóteles. Según Joseph Schumpeter, una de las pocas cosas resaltantes en el discurso de Platón acerca de la economía es su visión sobre el sistema de castas. Esta solo reflejaría la necesidad de una división del trabajo. Para Platón esta división aumentaría los niveles de eficiencia de la sociedad. En términos modernos, existe en Platón un defensor de la especialización. Además, Platón observa "que el dinero es un símbolo arbitrario para facilitar el intercambio" 51 . Pero el filósofo no hizo del dinero un objeto de reflexión. Aunque haya momentos de su obra en los cuales se muestre hostil al uso del oro y de la plata o crea conveniente el uso de una moneda que no pueda emplearse fuera de los límites del Estado. Muchas ideas sobre Platón en torno a la economía están tomadas del Eryxias que es un escrito cuya autenticidad ha sido puesta en duda. De todos modo, las doctrinas defendidas en dicho diálogo, desde el punto de vista de Schumpeter, no contradicen en nada las doctrinas conocidas de Platón. El diálogo ha sido tomado por una carencia de fuentes. A pesar de lo cual, Schumpeter afirma que el texto no presenta interés alguno.

Por el contrario, el discurso de Aristóteles muestra características importantes. Ya en el primer libro de La Política, Aristóteles estudia la crematística y el uso de la moneda. Tanto el libro primero de la Política como el libro quinto de la Ética a Nicómaco contienen lo más importante de las doctrinas económicas aristotélicas. Pero debido a que nuestro objeto específico de investigación es el libro quinto de la Ética a Nicómaco, revisemos cuál es el planteamiento.

Aristóteles intenta explicar que las comunidades se mantienen unidas por un factor que llama "la reciprocidad basada en la proporción y no en la igualdad" (EN 1132b 32-33). Al referirnos antes a la justicia distributiva hacíamos alusión a una justicia basada en la proporción. Aquí la reciprocidad se encuentra también basada en la proporción, pero el filósofo intenta establecer cuál es la diferencia con la justicia distributiva. 
Debido a que los productos de intercambio no son iguales, entonces se deberá recurrir a una lógica proporcional. Así, lo que produce un arquitecto y lo que produce un zapatero son cosas diferentes. Sin embargo, podemos igualar esos dos productos si decimos que son proporcionalmente iguales. Un zapato no es igual a una casa. Pero doce zapatos es probable que equivalgan a una casa.

Es obvio que la sociedad funciona a partir del intercambio que se halla basado en una reciprocidad proporcional. Es decir, el intercambio no se da entre cosas iguales, sino entre cosas que pueden ser igualadas para que todos se abastezcan de lo necesario. Desde ese punto de vista, la vida social siempre implica el intercambio. La sociedad es un conjunto de intercambios ejecutados desde un principio de proporcionalidad.

Para que haya intercambio tiene que existir comparación ¿cómo se comparan dos productos? La comparación se da gracias a la moneda,

(...) quees dealgún modo, algo intermedio, porque todo lo mide, de suerte que mide también el exceso y el defecto: cuántos pares de sandalias equivalen a una casa o a un determinado alimento. Es preciso, pues, que entre el arquitecto y el zapatero haya la misma relación que hay entre una cantidad de zapatos y una casa o tal alimento. Pues de otro modo, no habrá cambio ni asociación (EN 1133a 20-25).

Veamos dos puntos. En primer lugar, Aristóteles nunca define la sociedad. La sociedad aparece como un acontecimiento natural, según sostiene en el libro primero de La Política. En el mismo texto, señala la unión de la comunidad con el fin de satisfacer algunas necesidades. En segundo lugar, desde los dos textos se puede colegir que la sociedad tiene por fundamento central la satisfacción de las necesidades basadas en el intercambio. Sin el factor del intercambio ¿qué sociedad podría imaginarse? "Si no fuera posible la reciprocidad no existiría asociación” (EN 1133b 5). El intercambio en un principio tal como nos explica en La Política se daba entre lo necesario. "Por ejemplo, dan vino y reciben a cambio trigo, o cualquier cosa análoga" 52 . Esa era la forma en la que los bárbaros aún en el tiempo de Aristóteles intercambiaban mercancías. Pero evidentemente esta forma de intercambio no hace uso de la crematística, porque abarca aún la economía. La diferencia entre las dos consiste en que en que mientras la primera se encarga de la administración de la casa; la segunda tiene por objeto la adquisición de bienes ${ }^{53}$ El intercambio sin dinero implicaba la necesidad de abastecerse de bienes, y forma parte de lo que Aristóteles llama un "acontecimiento natural" ${ }^{54}$.

La diferencia entre la economía y la crematística como algo natural y algo artificial respectivamente, explica también la condena que hace Aristóteles de la usura. La usura es la perversión de una finalidad convencional que es el intercambio. El dinero ha sido creado como convención para intercambiar bienes y la usura se sale de esa práctica común de intermediación. Ahora bien, ¿en qué momento del intercambio aparece el dinero? Según Aristóteles, desde el momento que se dependió más del exterior (del exterior de cada grupo que intercambiaba), de los productos 
útiles y se hizo más importante la exportación de lo que se tenía en abundancia, "la necesidad hizo que se ideara la utilización del dinero, por no ser fáciles de transportar todos los productos necesarios" 55 .

De este punto resulta claro la refutación de la posición de Schumpeter, según la cual, el intercambio de bienes es un producto de la situación de que no pueda existir una sociedad comunista al estilo de Platón. La visión del intercambio, según vemos, es más genetista como suelen ser muchos enfoques de Aristóteles. El realismo aristotélico siempre se impone; siempre parte de lo que existe, su afán es fundamentar lo que ya existe, lo cual lo sitúa en una condición conservadora.

En este punto, encontramos otro tema que puede ser enfocado: la moneda no era tan sólo un valor simbólico, sino que constituía, además, un objeto que fuera útil en sí mismo y de fácil manejo en la vida misma.

Al principio determinaron su valor simplemente por su tamaño y peso y por último le imprimieron un cuño para ahorrarse el trabajo de medirlo, ya que el cuño se puso para significar el valor ${ }^{56}$.

Según Schumpeter ${ }^{57}$, en este fragmento Aristóteles suscribiría la teoría metalista del dinero, en contraposición con una teoría nominalista del dinero. El dinero debe valer no sólo simbólicamente, sino que está hecho de materiales que le otorguen valor por sí mismos.

Esto crearía un problema advertido por el mismo autor: si Aristóteles es un partida- rio del valor del dinero por el material en el que este es trabajado, ¿cómo puede ser luego un partidario del convencionalismo de la moneda? Obviamente el uso de los metales puede ser entendida como otra convención.

La moneda tiene, además, características crediticias: "La moneda sirve como garante, porque el que tiene dinero debe poder adquirir" (EN 1133b 12-13). Además, la moneda está sujeta a las fluctuaciones. Sin embargo, Aristóteles es partidario de la permanencia del valor de la moneda. Por lo tanto, es partidario además de la estabilidad de los precios. La pregunta que se formula Schumpeter es por qué Aristóteles percibió con tanta justicia los precios que en ese momento existían. Pero se puede notar, luego de una lectura atenta de Aristóteles, la condena de los monopolios.

Para que las cosas sean conmensurables debe existir un acuerdo en torno al valor de las cosas. Por esto, Aristóteles defiende una visión convencional acerca del valor. Ciertamente, el texto es muy sugerente. El comentario de Karl Marx es insoslayable. Agnes Héller supone que la postura de Marx respecto de este texto de Aristóteles tiene importancia en la medida en que demuestra los límites del discurso aristotélico, "Aristóteles se daba cuenta de que dos cosas que según su proporción son mensurables, deben tener algo en común. Pero pensó también que ese algo común estaba en su necesidad social y no en el trabajo mismo. A saber, pensaba que el intercambio se efectuaba en relación proporcional a la necesidad" ${ }^{\prime 2}$. 
Marx menciona el texto de Aristóteles en el segundo capítulo del libro primero de El Capita ${ }^{59}$. La cita textual pertenece al primer libro de La Política. Como ya dijimos, dicho texto más el que trabajamos contienen el aspecto central de la doctrina económica en Aristóteles.

El objeto de disertación de Marx es el proceso del cambio y por cierto la aparición del dinero. Previamente, se establece la diferencia entre valor de uso y valor de cambio en las mercancías. El valor de uso implica la consideración de la mercancía por sus cualidades materiales. El valor de cambio es la utilización de la mercancía con la finalidad de intercambiar.

Sobre el mismo punto, Aristóteles nos dice lo siguiente:

Empecemos su estudio (se refiere a la crematística) con las siguientes consideraciones: todo objeto que se posee puede utilizarse como tal de dos maneras, pero no en el mismo sentido; una utilización es adecuada al objeto y la otra no, por ejemplo, la utilización de una sandalia como calzado y como objeto de cambio ${ }^{60}$.

Además, para Aristóteles la función del uso es natural mientras que la función propia del cambio es artificial. La sandalia ha sido hecha para usarse y no para ser intercambiada por otra mercancía.

En términos aristotélicos, la sandalia encuentra su fin en su propio uso (praxis), mientras que el intercambio vendría a ser el uso de la sandalia como instrumento (poiesis). Ciertamente, hay en Marx una impronta aristotélica. Para empezar, el proceso de intercambio de mercancías es un proceso social general. Este proceso es el que permite la subsistencia social. La diferencia radica en que mientras desde el punto de vista de Aristóteles se intercambian necesidades; en Marx el intercambio de mercancías implica el trabajo invertido en su elaboración ${ }^{61}$.

\subsection{La justicia política}

La introducción al parágrafo dedicado a la justicia política comienza preguntándose acerca de lo que define la injusticia. No somos viciosos porque hagamos una acción de tipo viciosa.

Es posible obrar injustamente sin ser injusto ¿Qué clase de acciones injustas ha de realizar uno para ser injusto con respecto a cada clase de injusticia, por ejemplo, para ser ladrón adúltero o bandido? (EN 1134a 15-20).

El comentario de Santo Tomás se orienta a demostrar sobre este punto que lo que cambia la naturaleza de la acción es la elección. Si hacemos algo de forma involuntaria no podemos ser considerados personas injustas $^{62}$.

Este texto es, en verdad, una entrada al examen de la justicia política. La justicia política sólo es posible en un contexto en el que existe autarquía. Tal como lo plantea Aristóteles para la Política, la autarquía implica una polis libre que no ha sido colonizada y que crea y promueve sus propias leyes. Como se sabe, al concepto de autarquía se debe sumar el concepto de autonomía. En el caso específico de la justicia política, Aristóteles está hablando de los ciudadanos o de las relaciones entre 
estos. La advertencia es para los hombres que gozan de autarquía. El objeto de su discurso son los hombres libres. Al referirse a los hombres libres está excluyendo implícitamente a los esclavos, a las mujeres y a los menores de edad ${ }^{63}$. No en vano el público al que se dirige también en el primer libro de la Política es el conjunto de hombres dispuestos a hacer vida política. Es decir, aquí se habla de aquellos que pueden gobernar y ser gobernados. Como es de consenso entre los especialistas, Aristóteles habría dirigido sus tratados prácticos (La Etica y La Política) a los hombres libres que participan de la vida pública.

Por lo demás, solo es posible hablar de justicia política en el caso de las personas que son iguales aritméticamente o proporcionalmente ya que

(...) entre personas que no estén en estas condiciones, no es posible la justicia política de los unos respecto de los otros, sino sólo la justicia en un sentido y por analogía (EN 1134ª 25-30).

¿Puede haber injusticia desde el punto de vista aristotélico entre un amo y su esclavo? La respuesta de Aristóteles es negativa, como veremos más adelante. En general, la ley que obliga al cumplimiento de la justicia es solo para los hombres libres. La ley contempla las diversas formas de injusticia, pero estas solo contemplan las figuras relativas a los hombres libres. Sería como decir contemporáneamente que no pueden existir derechos para aquellos que no son considerados ciudadanos. Aunque en las sociedades actuales los niños y los discapacitados mentales sean sujetos rela- tivos de derecho, es decir, tienen derechos ya que nadie puede secuestrarlos o robarles sin que eso implique un castigo, pero no pueden ejercer cargos políticos.

La ley no puede estar en manos de un hombre

porque el hombre manda en interés propio y se convierte en tirano. El magistrado en cambio es el guardián de la justicia, y si de la justicia, también de la igualdad (EN 1134a30-35).

Aristóteles al igual que Platón rechaza la tiranía. Este, como vimos antes, vincula la tiranía a la sofística (como en El Gorgias). De otro lado, Aristóteles aunque es partidario de las leyes en un sentido fuerte, es además partidario de la autoridad de los magistrados (árchontes). Estos en la Atenas antigua eran elegidos por sorteo. Los arcontes, eran los que aseguraban la permanencia del poder de un sector social. Su vigencia duró entre el siglo octavo antes de cristo al siglo tercero después de Cristo. En la Constitución de Atenas, Aristóteles ha dejado un documento acerca del interrogatorio al que eran sometidos por el Areópago (consejo constituido por arcontes) para ser aceptados en el cargo. Todas las preguntas eran relativas a la progenie de los aspirantes a ocupar cargos públicos. Para Aristóteles, la autoridad de los arcontes era indispensable para el funcionamiento de la ley.

Más adelante, dice: "La justicia del amo y la del padre no son las mismas que la de los gobernantes, pero sí semejantes" (EN 1134 9-10). Ya vimos en el primer libro de La Política que la motivación 
central a partir de la cual surgen los demás argumentos es la demostración de que el gobierno de la casa no es igual al gobierno de la ciudad, razón por la cual analiza las relaciones al interior de la casa. Esta desemejanza se sostiene porque además las relaciones al interior de la casa son entre desiguales, mientras que las relaciones en la polis son entre iguales. Así las relaciones entre un ciudadano y su mujer, un ciudadano y su hijo o un ciudadano y su esclavo, son relaciones que Aristóteles considera como de uno consigo mismo, ya que todo lo doméstico le pertenece al ciudadano como si fuera él mismo. Más adelante desarrollará de forma más extensa la idea:

Por eso no hay injusticias para con uno mismo y, por eso, tampoco hay injusticia ni justicia en el sentido político. Pues esta justicia era de acuerdo con la ley y existía entre aquellos que tienen ley de un modo natural, es decir, aquellos que son iguales en el mando y en la obediencia. De ahí que la justicia se aplica más a la mujer que a los hijos o a la propiedad; y ésta es la justicia doméstica, que es distinta de la política” (EN 1134 10-20).

Una justicia doméstica estará ordenada según un criterio que considera más importante a la mujer que al hijo o al esclavo. Sin duda, la mujer aparece como más semejante al ciudadano que los hijos o los esclavos.

\subsection{La justicia natural y la justicia le- gal}

Esta disyuntiva entre justicia natural y legal ha fundado muchas de las controversias posteriores. Del lado de los que defienden el iusnaturalismo tomista este párrafo puede tener una importancia fundamental.

"La justicia política se divide en natural (fisicón) y legal (nomikón)" (EN 1134 15 20). La distinción entre una justicia natural y otra legal radica en que la justicia natural es en todas partes igual y no está sujeta al parecer humano; legal en cambio es la considera en un principio que los actos puedan ser así o de otra manera pero una vez que pretenden especificar adquieren formas diferentes. Por ejemplo que el rescate de alguien cueste una mina o que se deba sacrificar dos becerros y no dos ovejas. El carácter de la justicia en estos casos es puramente convencional.

¿A quiénes se refiere Aristóteles cuando dice: "algunos consideran que toda justicia política es de esta clase" (EN 1134 25 )? Aunque la alusión nunca es explícita, se refiere, como en otros puntos, al discurso de los sofistas que habían relativizado la moral. En especial, alude a Antifonte, partidario de la abolición del Estado y de la esclavitud. Más adelante afirma:

(...) pues lo que existe por naturaleza es inamovible y en todas partes tiene la misma fuerza, como el fuego que quema tanto aquí como en Persia, mientras que las cosas justas observan ellos que cambian. Esto no es así aunque lo es en un sentido. Quizá entre los dioses no lo sea de ninguna manera, pero entre los hombres hay una justicia natural $y$, sin embargo, toda justicia es variable aunque hay una justicia natural y otra no natural (EN 1134 25-30).

Aquí empieza a presentarse un matiz que hará posible la objeción de algunos auto- 
res que ven la debilidad de un supuesto iusnaturalismo en Aristóteles. En otras palabras, el filósofo no hace mención de una sola regla que sea considerada propia de la justicia natural. Aunque más adelante afirme:

Ahora, de las cosas que pueden ser de otra manera está claro cuál es natural y cuál no es natural sino legal o convencional, aunque ambas sean igualmente mutables (EN 1134' 30).

¿Porqué da por supuesto que todos pueden distinguir una norma natural? Digamos que el ejemplo aristotélico recurre como una suerte de última instancia a la evidencia del ethos. Es decir, todos están de acuerdo por consenso con las costumbres de aquello que puede sancionar una norma.

Es interesante comprobar el ejemplo aristotélico relativo a los dioses. En los dioses no hay justicia natural. Cabe interpretar que siendo los dioses superiores no hay ninguna regla que se les imponga o, más aún, que ellos son las reglas. Podría creerse que al no encontrarse atados por normas, cada uno de sus actos constituye una norma en sí misma.

Ahora bien, tal como señalamos en un párrafo anterior cabe la posibilidad de que Aristóteles aluda a las acciones malas en sí mismas consideradas así en el libro segundo de la Ética a Nicómaco como el adulterio o el desear mal a otra persona ${ }^{64}$.

Sin embargo, para Carnes Lord ${ }^{65}$, el filósofo griego no habría mencionado una sola norma con esas características de universalidad y, más bien "Aristóteles no aprueba la idea de que haya unos primeros principios, inmutables, que sirven aunque de manera remota si se quiere, como guía de la práctica real"66.

Sobre el punto hay una controversia fundada en la tradición interpretativa que nace en Tomás de Aquino. Efectivamente, Tomás de Aquino asume la defensa de una justicia que tendría como base lo natural. Reproduce el argumento de Aristóteles, según el cual en Aristóteles lo natural se revela de dos maneras: por su efecto o virtualidad o lo natural como causa ${ }^{67}$.

En todo caso lo que pretende mostrar es que existen males naturales que deben evitarse como ser dañado injustamente o robar. Se establece la diferencia entre el derecho natural y el derecho de gentes. Los dos nacen de una concepción natural acerca del hombre. El primero de la condición de animal racional del hombre; el segundo se llama así porque todas las personas lo practican.

Asimismo se llama justo legal a lo que la ley impone; a los casos de excepción que ingresan en lo que se denomina la ley privada y a las sentencias de los jueces ${ }^{68}$. La intención de Tomás de Aquino es demostrar que la justicia legal se halla fundada en la justicia natural. De esta manera, robar es algo sancionable naturalmente (derecho natural), pero el derecho legal establece el tipo de pena que convenga.

Tomas de Aquino reproduce el pensamiento de un sector de la filosofía griega de aquella época que veía que sólo existen leyes positivas. En esta línea, se halla no sólo Antifón (a quien el Aquinate no men- 
ciona), sino Aristipo, filósofo socrático ${ }^{69}$.

Debe quedar establecido, según Tomás de Aquino, el concepto de lo natural como aquello que consideramos universal. Sin embargo, el hombre es una mezcla de cosas naturales y de otras que no lo son. Hay una base natural en el hombre de la que se sigue lo demás. El hombre es por naturaleza animal, pero sus disposiciones y sus movimientos son relativos. Del mismo modo, hay imperativos morales que son naturalmente condenables como el robo. Sin duda, la visión de Tomás de Aquino en este caso específico se aproxima a lo que podemos llamar un "esencialismo moral". La ley positiva proviene de la ley natural es advertir que existe un orden que nunca va a ser modificado radicalmente ya que sus bases están cimentadas en lo inmodificable.

Cabe preguntarse desde fuera del argumento qué llevaba a Aristóteles a considerar que existía una justicia natural y la respuesta se encuentra en los interlocutores implícitos en el discurso. Debo referirme una vez más a los sofistas. Uno de los más importantes, Antifón, sostenía lo siguiente: "La justicia consiste en no transgredir los preceptos legales de la ciudad de que es ciudadano. Un hombre puede conducirse irreprochablemente en armonía con la justicia si ante testigos defiende las leyes y cuando está solo sin testigos, sostiene, en cambio, los dictados de la naturaleza. En efecto, las disposiciones de la ley son artificiales, mientras que las de la naturaleza son necesarias. Y las leyes existen por coacción, no por necesidad, mientras que las exigencias de la naturaleza no son motivo de convención.
A decir verdad, un hombre que infringe la ley queda libre de oprobio y de castigo en tanto no es observado por quienes guardan las convenciones. Distinto es el caso de los dictados de la naturaleza. Si estos no son eludidos por alguien, las consecuencias no son menos graves porque nadie lo observe y ellos se debe a que la vergüenza no le alcanza en virtud de la opinión de los hombres, sino de la verdad, (...) la mayoría de las acciones justas según la ley son juzgadas hostiles para la naturaleza. Hay ya convención en lo que los ojos deben ver o no ver en lo que los oídos les está permitido oír o no oír; en cuanto a la lengua, en lo que debe decir o no decir; referente a las manos, en lo que deben hacer o abstenerse de hacer; (...) y en cuanto al intelecto, en lo que le es dado pensar y lo que no ha de pretender (...). No es verdad por lo menos según a correcta comprensión, que el dolor beneficie más a la naturaleza que el placer ni que lo que entristece sea más ventajoso que lo que alegra"70.

A primera vista puede sorprender que un sofista, es decir, un militante de posturas que relativizan en gran medida el pensamiento tradicional, sea partidario de una moral natural. Sin embargo, de otro lado es completamente coherente que así sea. Al hablar de moral natural, Antifón no habla de lo universal, no está refiriéndose a unos valores en los que todos se verían reconocidos, sino, más bien, de una postura individualista como bien ha anotado Agnes Héller ${ }^{71}$. Así como Aristóteles habría considerado que la ley natural es todo aquello en lo que coincidimos, la ley natural de Antifón es individualista. Las aspiraciones del individuo están en con- 
flicto con la comunidad. Esta ha encontrado una regulación en las normas y son las normas, precisamente las que se oponen a la realización individual.

La ley natural de Antifón, por tanto no parece a la ley natural planteada por Aristóteles (que son las costumbres morales que se prolongan en el transcurso del tiempo) y luego por Tomás de Aquino para quien la ley natural es la ley de Dios.

Es fácil establecer el vínculo entre Federico Nietzsche y Antifón, aunque Héller lo vincula -incluso por sus ideas económicas- con el liberalismo inglés. En todo caso, resulta del todo importante decir que mientras el apoyo a las legislaciones equivale a un apoyo a la comunidad, el ataque a las leyes positivas es en el caso de Antifón es una actitud de rebeldía extrańa contra la comunidad.

De otro lado, es dudosa la presentación que hace Héller de Antifón. Las ideas relativas al dinero que van a fundar el capitalismo, según Max Weber, aparecen mucho después.

\subsection{La equidad e iinjusticia consigo mismo?}

Respecto de lo equitativo, como en todos los otros casos, se nos presenta una controversia. Lo más importante se resume en considerar que lo equitativo no es mejor que lo justo como si se tratara de otro tipo de justicia. Por otro lado:

"Así, lo justo y lo equitativo son lo mismo, y aunque ambos son buenos, es mejor lo equitativo" (EN 1137 10)
En realidad, lo equitativo aparece como una posibilidad de corregir la ley. La justicia es tan solo una contemplación de la generalidad, pero los casos específicos revelan una insuficiencia de la ley, es decir, revelan figuras que no están contempladas por la ley. El mismo Aristóteles lo plantea de la siguiente manera:

Lo que ocasiona la dificultad es que lo equitativo, si bien es justo, no lo es de acuerdo con la ley, sino como una corrección de la justicia legal. La causa de ello es que toda ley es universal y hay casos en lo que no es posible tratar las cosas rectamente de un modo universal (EN 1137 15-20).

Uno de los temas más importantes contemplados por el discurso es el caso del error. El error desde el punto de vista de Aristóteles: “(...) no radica en la ley, ni en el legislador, sino en la naturaleza de la cosa, pues tal es la índole de las cosas prácticas" (EN 1137 20$)$.

Cuando hay circunstancias que permanecen fuera de la fórmula universal y el legislador comete el error de intentar adaptar la ley a un caso específico, entonces la equidad permite una corrección de la ley.

$Y$ tal es la naturaleza de lo equitativo: una corrección de la ley en la medida en que su universalidad la deja incompleta (EN $1137^{\mathrm{b}} 25-30$ ).

La equidad pretende aplacar el rigor de la ley y adaptar la ley a una situación concreta. La defensa que hace Aristóteles de la equidad nos lleva por la senda de la legislación. Una vez más el entusiasmo de Aristóteles por la legislación y por la actividad 
concreta de los legisladores lo diferencia de Platón o por lo menos del Platón de $L a$ República, aunque pueda considerarse que el Platón de las Leyes es más entusiasta de las leyes que de la clase dirigente que las haría cumplir.

Por todo lo dicho cabe, sin embargo, preguntarse si es posible ser injusto consigo mismo.

Lo justo y lo injusto requiere más de una sola persona. Además la injusticia tiene que ser voluntaria, intencionada $\mathrm{y}$ anterior en el tiempo, porque no se considera que obre injustamente el que devuelve lo mismo que ha sufrido, pero si se trata de uno mismo es víctima y promotor al mismo tiempo. Además sería posible ser tratado con injusticia voluntariamente. Finalmente, nadie obra injustamente sin cometer algún acto particular de injusticia y nadie comete adulterio por su propia mujer, ni allana su propia casa, ni roba lo que le pertenece (EN 1138a 20).

La única forma de justicia contra uno mismo es aquella que no es exactamente contra nosotros mismos sino contra ciertas partes de nosotros mismos. Esta es una forma metafórica de hablar de las relaciones al interior de la casa. Puede ser que existan personas al interior de la casa que sufran un tipo de trato análogo al de la injusticia.

Es menester comentar que este fragmento refleja en gran medida la inexistencia de lo que luego de Sigmund Freud ha denominado neurosis. Por lo menos, desde un punto de vista general se desconoce la noción de lo autodestructivo. Ello se pue- de colegir fácilmente del texto de Aristóteles. Es imposible una injusticia contra uno mismo porque la autodestrucción y los conflictos con el yo deben esperar la modernidad que traerá consigo la noción de individuo.

\section{Conclusiones}

1. La justicia es un principio equívoco. $\mathrm{Su}$ equivocidad se encuentra fundada en la diversidad de opiniones y de prácticas morales propias de la polis griega. Esto implica que dichas formas corresponden a diferentes procedimientos relacionados con la ley y con las prácticas mercantiles.

2. La injusticia es trasgresión de la ley en la medida en que la ley ordena todos los aspectos de la vida según Aristóteles. Aunque nunca se llega a demostrar que la ley se ocupe de todos los aspectos de la vida, permanece como una pretensión que así sea.

3. El entusiasmo por las legislaciones en Aristóteles surge de su ataque al relativismo moral. En el contexto de la época, las escuelas sofísticas y algunos filósofos como Aristipo y Antifón habían puesto en entredicho el fundamento de la ley. La idea de Aristóteles según la cual la ley siempre encarna la justicia juega un rol a favor de la justicia ya existente en la polis.

4. La división entre justicia universal y justicia particular separa la preocupación de la justicia como una virtud abstracta de la justicia como un criterio regulador del mercado. 
5. La sociedad es para Aristóteles un sistema de intercambios con el fin de abastecer sus necesidades. La justicia correctiva y la distributiva sirven para regular esos intercambios.

6. La justicia distributiva es la justicia política por excelencia. Discute acerca de cuál debe ser el criterio para la distribución de los bienes. Este punto funda la noción de regímenes políticos, en la medida en que señala el rol del Estado.

7. La justicia de la reciprocidad es la que rigió en el mundo arcaico y es la que rige en el mercado, en alguna medida ( reciprocidad proporcional).

8. La moneda sirve para medir los bienes e intentar igualarlos en el intercambio.

9. La diferencia entre justicia natural y justicia legal fundan algunas tradiciones como la del iusnaturalismo teológico.

10. La principal pretensión de los iusnaturalistas es demostrar que la ley positiva se encuentra fundada en la ley natural.

11. Finalmente, es imposible la injusticia contra uno mismo porque no existe noción de individuo y la polis está por encima de sus ciudadanos.

\section{Notas}

1 Para este estudio me sirvo de las traducciones de la editorial Gredos,
2004, y del Centro de Estudios Constitucionales, 1985. En adelante abreviaré EN = Etica a Nicómaco.

2 Véase Aristóteles De ánima, Lib. I.

3 Oswaldo Guariglia, La ética en Aristóteles o la moral de la virtud, p 263.

4 Norberto Bobbio, Estado y gobierno y sociedad, p. 97.

5 Gabriel Icochea Rodríguez, Origen de la comunidad y teoría de la esclavitud en Aristóteles, Investigación de Bachillerato, Facultad de Teología Pontificia y Civil de Lima.

6 Christopher Rowe, Introducción a la Ética Griega, p. 25.

7 Alasdair MacIntyre, Justicia y Racionalidad, p. 32.

8 Hesíodo, Teogonia, 900-905.

9 Véase Rodolfo Mondolfo, La conciencia moral de Homero a Demócrito y Epicuro, pp. 28-29.

10 Hesíodo, Los trabajos y los dias, 225234.

11 Ibid. 240- 248.

12 Véase Werner Jaeger, Paideia, p. 295.

13 Ibid, p. 77.

14 Francisco Rodríguez Adrados, La democracia ateniense, p. 75.

15 Citado por Rodríguez Adrados, op. cit. p. 75 .

16 Véase Francisco Rodríguez Adrados, op. cit., p. 77.

17 Ibid. p. 78.

18 Ibid. p. 142.

19 Idem.

20 Francisco Rodríguez Adrados. op. cit., p. 283

21 William Guthrie Historia de a filosofía griega IV, p. 417.

22 Idem.

23 Christopher Rowe, ob citada, p. 90. 
24 La República, 331b.

25 Platón La Rep, 331e.

26 Véase Gómez Robledo, Platón. Los seis grandes temas de su filosofía, p. 549.

27 Citado por Gómez Robledo, op. cit. p. 548.

28 William Guthrie, ob. cit. p. 428.

29 Gabriel Icochea Rodríguez, Origen de la comunidad y teoría de la esclavitud en La Política de Aristóteles, p. 14.

30 Tomás de Aquino, Comentarios a la Etica a Nicómaco, p. 287

31 Véase EN 1099b 5.

32 Véase Agnes Héller, Aristóteles y el mundo antiguo, pp. 33 ss.

33 Santo Tomás, op. cit. p. 291.

34 Martínez Barrera, La Politica en Aristóteles y en Santo Tomás de Aquino, p. 58.

35 Roberto Aramayo, La quimera del rey filósofo, p. 28.

36 Karl Popper, La sociedad abierta y sus enemigos, p. 139.

37 Martínez Barrera, op cit. p. 58.

38 Citado por William Guthrie, op. cit., tomo V, p. 384.

39 William Guthrie, op. cit. p. 384.

40 Oswaldo Guariglia, op. cit. p. 270.

41 Véase, Platón, La República, Libro VIII.

42 Véase Aristóteles, La Politica Lib. III.

43 Norberto Bobbio, Estado gobierno y sociedad, p. 84.

44 Alasdair MacIntyre, Justicia y racionalidad, p. 116.

45 Ibid. p. 115.
46 Ibid, p. 118

47 Carnes Lord, en: Leo Strauss y Joseph Cropsey (compiladores) Historia de la filosofia politica, p. 132.

48 Rodolfo Mondolfo, Conciencia moral de Homero a Demócrito y Epicuro, p. 29.

49 Ibid, p. 30

50 Tomas de Aquino, op. cit. lección VIII, 686, p. 308.

51 Joseph Schumpeter, Historia del análisis económico, p. 92.

52 Aristóteles, La Política, 1257a 25.

53 Ibid. 1256a 10

54 Ibid. 1257a 25.

55 Ibid. 1257a 30.

56 Ibid. 1257a 35.

57 Joseph Schumpeter, op. cit. p. 100.

58 Agnes Héller, op. cit. p. 353.

59 Karl Marx, El Capital, p. 49.

60 Aristóteles, La Politica, 1257a 5 -10.

61 Karl Marx, op. cit. p. 54.

62 Tomás de Aquino, op. cit. p. 318.

63 Fustel De Coulanges, La ciudad antigua, p. 167.

64 Véase EN 1107a 15.

65 Carnes Lord, en: Leo Strauss y Joseph Cropsey, op. cit. pp. $132-133$.

66 Ibid. p. 133

67 Véase Tomás de Aquino, op. cit. p. 322.

68 Ibid. p. 323.

69 Ibid. p. 324.

70 Citado por Agnes Héller, op. cit. pp. 33-34.

71 Ibid. p. 35. 


\section{Bibliografía}

\section{Obras de Aristóteles}

ARISTÓTELES. Metafísica. Madrid, Editorial Gredos, 1987.

La Política. Madrid, Editorial Gredos, 1999.

Ética a Nicómaco. Barcelona, Editorial, Gredos, 2004.

Ética a Nicómaco. Madrid, Ediciones CentrodeEstudios Constitucionales, 1985.

Gredos, 1978.

De anima. Madrid, Editorial

\section{Sobre Aristóteles}

AQUINO, Tomás De. Comentarios a la Ética a Nicómaco. Ediciones Universidad de Navarra, 2001.

ASPE ARMELLA, Virginia. El concepto de la técnica y la producción en la filosofía de Aristóteles. México, Editorial FCE, 1993.

AUBENQUE, Pierre. La prudence chez Aristote. París, Editorial Quadrige, 1993.

BAUER, Edgar. La physis en Aristóteles. Lima, Editorial PUCP, 1976.

DURING, Ingemar. Aristóteles. México, Ediciones UNAM, 1990.

GUARIGLIA, Oswaldo. La ética en Aristóteles o la moral de la virtud. Buenos Aires, Editorial Eudeba, 1997.

HELLER, Agnes. Aristóteles y el mundo antiguo. Barcelona, Editorial Península, 1998.
ICOCHEA RODRÍGUEZ, Gabriel. Origen de la comunidad y teoría de la esclavitud en Aristóteles. Investigación de bachillerato, $\mathrm{Fa}$ cultad de Teología Pontificia y Civil de Lima. Lima, 2005.

JAEGER, Werner. Aristóteles. México, Fondo de Cultura Económica, 1984.

MARTÍNEZ BARRERA, Jorge. La política en Aristóteles y en Santo Tomás de Aquino. Cuadernos de anuario filosófico, Ediciones Universidad de Navarra, 2001.

\section{Complementaria}

ARAMAYO, Roberto. La quimera del rey filósofo. Madrid, Editorial Taurus, 1997.

ARENDT, Hannah. La condición humana. Barcelona, Editorial Seix Barral, 1974.

BOBBIO, Norberto. Estado y gobierno y sociedad. México, Editorial Fondo de Cultura Económica, 2005.

GÓMEZ ROBLEDO, Platón. Los seis grandes temas de su filosofía. México, Editorial FCE, 1974.

GUTHRIE, William. K. C. Historia de la filosofía griega. Tomo IV. Madrid, Editorial Gredos, 1993.

Historia de la filosofía griega. Tomo V. Madrid, Editorial Gredos, 1993.

HESIODO. Los trabajos y los días. Madrid, Alianza Editorial, 1984.

Editorial, 1984.

Teogonía. Madrid, Alianza

JAEGER, Werner. Paideia. México, Editorial FCE, 1987. 
MACINTYRE, Alasdair. Tras la virtud. POPPER, Karl. La sociedad abierta y sus Barcelona, Editorial Crítica, 1987. enemigos. Buenos Aires, Editorial Paidós, 1981.

Justicia y racionalidad. Barcelona,

Ediciones Universitarias Internacionales, 1994.

MONDOLFO, Rodolfo. Conciencia moral de Homero a Demócrito y Epicuro. Editorial Universitaria de Buenos Aires, 1962.

NUSSBAUM, Martha C. La fragilidad del bien. Fortuna y ética en la tragedia y la filosofía griega. Madrid, Editorial Visor, 1995.

PLATÓN. La República. Madrid, Editorial Gredos, 1986.

RODRÍGUEZ ADRADOS, Francisco. La democracia ateniense. Madrid, Alianza Editorial, 1973.

ROWE, Christopher. Introducción a la Ética Griega. México, Fondo de Cultura Económica, 1993.

SCHUMPETER, Joseph. Historia del análisis económico. Barcelona, Ediciones Ariel, 1971.

STRAUSS, Leo y CROPSEY, Joseph (compiladores). Historia de la filosofía política. México, Editorial Fondo de Cultura Económica, 1993. 